\title{
A ring-width-based reconstruction of June-July minimum temperatures since AD 1245 from white spruce stands in the Mackenzie Delta region, northwestern Canada
}

Post-print/Accepted manuscript

Trevor J. Porter

Michael F.J. Pisaric

Steven V. Kokelj

Peter deMontigny

Porter, T.J., Pisaric, M.F.J., Kokelj, S.V., deMontigny, P. (2013). A ring-width-based reconstruction of JuneJuly minimum temperatures since AD 1245 from white spruce stands in the Mackenzie Delta region, northwestern Canada. Quaternary Research, 80(2), 167-169. doi: 10.1016/i.yqres.2013.05.004

\section{HOW TO CITE TSPACE ITEMS}

Always cite the published version, so the author(s) will receive recognition through services that track citation counts, e.g. Scopus. If you need to cite the page number of the TSpace version (original manuscript or accepted manuscript) because you cannot access the published version, then cite the TSpace version in addition to the published version using the permanent URI (handle) found on the record page. 
1 A ring-width-based reconstruction of June-July minimum temperatures since AD 1245 from

2 white spruce stands in the Mackenzie Delta region, northwestern Canada

4 Trevor J. Porter ${ }^{1,2, *}$, Michael F.J. Pisaric ${ }^{2,3}$, Steven V. Kokelj ${ }^{4}$, and Peter deMontigny ${ }^{2}$

$5 \quad{ }^{1}$ Department of Earth and Atmospheric Sciences, University of Alberta, Edmonton, Canada

$6 \quad{ }^{2}$ Department of Geography and Environmental Studies, Carleton University, Ottawa, Canada

$7 \quad{ }^{3}$ Department of Geography, Brock University, St. Catharines, Canada

$8{ }^{4}$ Renewable Resources and Environment, Aboriginal Affairs and Northern Development Canada,

9 Northwest Territories Geoscience Office, Yellowknife, Canada

10

11 *Correspondence. Tel.: +1-780-492-0832; Fax: +1-780-492-2030; E-mail: porter@ualberta.ca;

12 URL: http://www.tjporter.webs.com

13

14 Keywords: Mackenzie Delta; white spruce; tree-ring width; divergence; dendroclimatology;

15 temperature reconstruction

16

17

18

19

20

21

22

23 


\section{Abstract}

2 We present a reconstruction of June-July minimum temperatures since AD 1245 for the

3 Mackenzie Delta region based on a 29-site network of white spruce (Picea glauca) ring-width

4 series. Most, but not all trees experienced a divergent temperature-growth response, similar to

5 the divergence that has affected other white spruce trees across Yukon and Alaska. However,

6 divergence in the study region began as early as AD 1900 and we have documented our methods

7 to avoid including divergent signals in the reconstruction. Calibration/verification testing based

8 on local temperature data, and multi-century coherence with nearby and large-scale temperature

9 proxy records, confirm our reconstruction is robust. The reconstruction shows cool conditions in

10 the late $13^{\text {th }}$, early $18^{\text {th }}$ and early $19^{\text {th }}$ centuries, corresponding with solar minima and increased

11 volcanism. These cool periods are interrupted by warm periods consistent with early to mid- $20^{\text {th }}$

12 century warmth. The late $20^{\text {th }}$ century is the warmest interval, and the last decade is estimated to

13 be $1.4^{\circ} \mathrm{C}$ warmer than any decade before the mid- $20^{\text {th }}$ century. The reconstructed climate history

14 corroborates other proxy-based inferences and supports the notion that high-latitude regions such

15 as the Mackenzie Delta have experienced rapid warming in recent decades that is exceptional in

16 the last eight centuries.

18 Introduction

19 The circumpolar north has experienced rapid climate warming in recent decades (ACIA,

20 2005), which has stimulated a broad range of ecosystem-level changes (Tape et al., 2006; Bunn

21 et al., 2007; Turetsky et al., 2011; Lantz et al., 2012). However, Arctic climate is characterised

22 by a sparse network of instrumental records that are mostly shorter than 100 years in duration

23 (Lawrimore et al., 2011). This instrumental network is inadequate for evaluating regional-scale 
1 variability and providing the long-term context for recent climate changes. Climate proxies can

2 improve on existing knowledge of climate in northern regions, and tree-rings are ideal since they

3 are annually resolved and comparable to instrumental records (Hughes, 2011). Of interest to our

4 study is the development of millennial-length ring-width chronologies for climate reconstruction.

5 Such long chronologies are not found in all regions, either because the living trees are short-lived

6 or the environmental conditions are not suitable for deadwood preservation. Long chronologies

7 are more typical in northern Eurasia, but are virtually absent in northern North America (Jansen

8 et al., 2007). Here we focus on the Mackenzie Delta region, which hosts Canada's northernmost

9 treeline extent and has potential for multi-centennial- to millennial-length, climatically sensitive

10 tree-ring chronologies (Szeicz and MacDonald, 1996; Bégin et al., 2000; Pisaric et al., 2007).

11 A network of temperature-sensitive white spruce (Picea glauca) ring-width series, from

1210 existing and 19 new sites (Fig. 1), is used to develop a regional chronology and reconstruct

13 June-July minimum temperatures since AD 1245. Most trees in this network shared a divergent

14 temperature-growth response during the $20^{\text {th }}$ century (Pisaric et al., 2007) that is consistent with

15 the 'divergence problem' reviewed by D'Arrigo et al. (2008). The divergence we observe in the

16 Mackenzie Delta began as early as ca. AD 1900, which is earlier than in most other regions, and

17 we document our methods to avoid including divergent signals in our regional chronology.

18 Our regional chronology improves upon several previously developed chronologies from

19 the region as it represents one of the densest tree-ring networks ever compiled in northwestern

20 North America (NWNA), allowing us to isolate regional growth patterns linked to climate and

21 attenuate site- and tree-specific noise (Hughes, 2011). The reconstruction quality is demonstrated

22 by standard calibration and verification tests (Cook and Kairiukstis, 1990) over the instrumental

23 period, and multi-century coherence with temperature proxy records from neighbouring regions, 
1 and from large-scale Arctic and hemispheric networks. Our reconstruction provides a long-term

2 context for evaluating the significance of recent warming in the Mackenzie Delta region.

4 Background

5 Three notable ring-width studies on white spruce have been published from the

6 Mackenzie Delta region: Szeicz and MacDonald (1996), Bégin et al. (2000), and Pisaric et al.

7 (2007). Szeicz and MacDonald (1996) and Bégin et al. (2000) developed two of the longest

8 chronologies back to AD 1060 and 1172, respectively. The Bégin et al. (2000) chronology was

9 developed from living trees and deadwood snags (i.e., resting on the surface) from an isolated

10 stand in the Eskimo Lakes district, north of treeline (site 1 - Fig. 1). As is typical of trees from

11 cold, high-latitude regions, their chronology was positively correlated with summer temperatures

12 and was used to reconstruct temperatures. Conversely, Szeicz and MacDonald (1996) sampled

13 trees from rocky outcrops on Campbell Dolomite Upland (CDU; site 3 - Fig. 1) and found their

14 chronology was moisture-sensitive due to its inverse correlation with prior-summer temperatures

15 and positive correlation with annual precipitation. More recently, the CDU chronology has been

16 interpreted as a proxy for summer temperature (Esper et al., 2002; Frank et al., 2007; Porter and

17 Pisaric, 2011). Comparisons against other temperature proxies suggest the CDU chronology had

18 responded positively to temperature before the $20^{\text {th }}$ century, but shifted to a negative temperature

19 response in the $20^{\text {th }}$ century (Porter and Pisaric, 2011). Similarly, temperature-growth divergence

20 is found in other white spruce stands across NWNA (Jacoby and D'Arrigo, 1995; D'Arrigo et al.,

21 2004; Wilmking et al., 2004; Pisaric et al., 2007; Porter and Pisaric, 2011).

22 Pisaric et al. (2007) were the first to examine the climatic response of individual trees at

23 sites in the Mackenzie Delta plain (sites 6-13, Fig. 1). They too found that temperature-growth 
1 divergence was widespread, but a subset of trees from several sites maintained a stable, positive

2 temperature response over the full $20^{\text {th }}$ century. The point of divergence is evident by comparing

3 separate chronologies developed from the means of divergent and divergence-free trees (referred

4 to as 'negative and positive responders' by Pisaric et al., 2007; sensu Wilmking et al., 2004). The

5 divergent population began exhibiting contrasting low frequency growth patterns as early as ca.

6 AD 1900. Prior to the point of divergence, divergent and divergence-free trees shared a common

7 growth pattern that was a positive function of temperature based on comparisons with long proxy

8 records (Porter and Pisaric, 2011).

9 While many trees across NWNA were susceptible to temperature-growth divergence,

10 others were not (Bégin et al., 2000; Wilmking et al., 2004; Pisaric et al., 2007; Porter and Pisaric,

11 2011). The spatiotemporal coverage of tree-ring and climate records in NWNA are limitations to

12 understanding the cause(s) of divergence and likelihood it occurred in the past (D'Arrigo et al.,

13 2008), which has implications for tree-ring-based climate reconstructions (Jansen et al., 2007).

14 However, mounting evidence suggests that temperature-growth divergence is unique to the $20^{\text {th }}$

15 century and was caused by a large-scale climatic forcing (Cook et al., 2004; Porter and Pisaric,

16 2011). Warming-induced drought stress is often blamed (Jacoby and D’Arrigo, 1995; Lloyd and

17 Fastie, 2002; McGuire et al., 2010), and proxy records do support the idea that the $20^{\text {th }}$ century

18 has been anomalously warm (D'Arrigo et al., 2006) and dry (Anderson et al., 2007, 2011). The

19 exceedance of temperature thresholds resulting in physiological stress has also been proposed

20 (D'Arrigo et al., 2004; Wilmking et al., 2004). However, not all trees in affected regions exhibit

21 a divergent response (Wilmking et al., 2004; Pisaric et al., 2007; Porter and Pisaric, 2011), which

22 implies that local-scale factors determine why some trees are susceptible and others not (Porter

23 and Pisaric, 2011). For example, stand density and surficial organic layer thickness are important 
1 soil hydroclimate moderating factors (Wilmking et al., 2004; King, 2009; Drobyshev et al., 2010;

2 Yarie and Van Cleve, 2010) and could influence a tree's susceptibility to divergence if related to

3 moisture stress.

4 Regardless, if temperature-growth divergence is unique to the $20^{\text {th }}$ century and has not

5 affected all trees, it should be possible to develop robust temperature reconstructions in regions

6 affected by divergence if careful selection procedures are used to exclude divergent signals from

7 the reconstruction (Wilson et al., 2007). Here, we re-examine the aforementioned tree-ring data

8 from the Mackenzie Delta region and develop a divergence-free regional chronology, which we

9 use to reconstruct summer temperatures over most of the last millennium.

\section{Methods}

12 Study area

13 The Mackenzie Delta is an alluvial feature of Holocene age comprised of sediments from 14 the Mackenzie and Peel Rivers (Mackay, 1963). White spruce trees dominate the delta plain and 15 grow in well-drained alluvium underlain by permafrost (Nguyen et al., 2009). Most delta plain

16 sites studied here (sites 6-29, Fig. 1) are open-canopy, white spruce/lichen-crowberry stands, as

17 described by Pearce et al. (1988), which have abundant mature trees, deadwood, and lichen cover

18 (e.g., Cladonia rangiferina; Caldina mitis; Supplementary Fig. 1). The development of ice-rich

19 permafrost has elevated these surfaces above the regular spring flooding level (Kokelj and Burn,

20 2005a), and has helped to prevent rot and preserve deadwood. The general absence of wildfires

21 in the delta also helps to preserve centuries-old trees and deadwood, making these site types well

22 suited for dendroclimatic research. 
Five upland sites examined here (sites 1-5, Fig. 1), adjacent to the Mackenzie Delta, are

2 broadly consistent with the delta plain sites in terms of canopy and understory structure, but they

3 differ in terms of surficial geology. Three of these sites (CDU, CDU1, and CDU2) are found on

4 the Campbell Dolomite Upland (Supplementary Fig. 2), a dolomite, quartzite, and shale outcrop

5 of Precambrian to Lower Devonian age (Norris, 1981). The area was overridden by Laurentide

6 ice between 14 and $21{ }^{14} \mathrm{C}$ ka BP (Dyke et al., 2002). Forested sites have only a shallow mineral

7 soil layer, presumably from weathered parent material or glacial till. The two other upland sites

8 (ESK and NL1) are isolated tundra stands on hummocky moraine deposits (Rampton, 1988).

9 Seasonal temperatures and precipitation are greatest in summer. Mean temperature

10 normals (AD 1971-2000) at Inuvik for the winter (DJF), spring (MAM), summer (JJA), and fall

11 (SON) seasons are $-26.7,-11.9,12.2$, and $-8.5^{\circ} \mathrm{C}$, respectively; the same seasonal normals for

12 total precipitation are 41.1, 38.5, 95.2, and $73.8 \mathrm{~mm}$ (http://climate.weatheroffice.gc.ca).

14 Tree-ring data

15 Nineteen white spruce stands (Table 1) were sampled in 2007 and 2008 using standard

16 dendrochronology methods (Speer, 2010). General sampling areas were preselected so that sites

17 would be well distributed across the region. Mature sites with abundant snags were targeted to

18 maximize the length of tree-ring chronologies. On average, 45 trees were sampled per site, most

19 of which (ca. $\geq 80 \%$ ) were living. A single bark-to-bark core (i.e., representing two radii) passing

20 through or near the pith was collected from living trees; 'cookies' were cut from snags. Samples

21 were sanded to a smooth finish so the rings could be visually cross-dated and measured using a

22 Velmex measuring system $( \pm 0.001 \mathrm{~mm})$. Two radii per tree were measured in nearly all cases.

23 Cross-dating accuracy was verified using the program COFECHA (Holmes, 1983). 
These 19 sites are supplemented by 10 previously sampled sites (Table 1): 8 eastern delta

2 sites - Pisaric et al. (2007); the Eskimo Lakes 'ESK' site - Bégin et al. (2000); and the Campbell

3 Dolomite Upland 'CDU' site - Szeicz and MacDonald (1996). Details about the ring-width data

4 from these sites are provided in Supplementary Note 1.

5 Age-related trends were removed from ring-width series using standard data-adaptive

6 negative-exponential or linear negative-to-zero slope curves (Fritts et al., 1969) following the

7 'signal-free' approach by Melvin and Briffa (2008). The signal-free approach improves upon

8 traditional tree-ring standardisation as it helps to avoid distortion caused by climate signals in

9 growth series. Ideally, an expected growth curve fitted to raw ring-width measurements should

10 reflect only the age-related trend (i.e., independent of climate). However, when data-adaptive

11 curves are used, they are unavoidably distorted (referred to as 'trend distortion') by the climate

12 signal. Removing these curves from raw data will, therefore, remove some of the original climate

13 signal. Because data-adaptive curves, determined by least squares, are most influenced by series

14 ends, trend distortion is also most severe at the ends of series. In the case of mean chronologies

15 where the modern ends of many standardised indices end on the same year (e.g., living trees) and

16 are averaged together, a large trend distortion may occur and cause a poor fit between the climate

17 series and mean chronology (Melvin and Briffa, 2008). Signal-free standardisation avoids trend

18 distortion by estimating and removing the common climate signal from each series, based on the

19 iterative procedure outlined by Melvin and Briffa (2008), resulting in 'signal-free measurements'

20 that can be used to better characterise age-related trends. However, it is important to note that

21 data-adaptive signal-free standardisation is subject to the same low-frequency limitations or

22 'segment length curse' (Cook et al., 1995) as more traditional methods, with potential loss of

23 low-frequency signals at wavelengths greater than the mean series length. 
A signal-free-enabled version of the program ARSTAN (provided by E. Cook, Lamont-

2 Doherty Earth Observatory) was used to calculate the standardised ring-width indices. Indices

3 belonging to the same tree were averaged into mean 'tree indices' (Supplementary Fig. 3). Site

4 and regional chronologies were calculated using the robust bi-weight mean (Cook, 1985).

$6 \quad$ Climate data

7 Regional composites of monthly minimum, mean and maximum temperatures and total

8 precipitation were developed from several nearby climate station records (Supplementary Fig. 4;

9 see Supplementary Note 2 for details on the regional composites) to allow the longest possible

10 comparisons between local climate and our tree-ring data. The temperature composites span AD

11 1892-2007 and are continuous only from AD 1910-2007 for most months (Supplementary Figs.

12 5-7). The total precipitation composites span AD 1926-2007, continuously (Supplementary Fig.

13 8). Temperature variability is coherent across the region, but total precipitation is more spatially

14 heterogeneous (Burn and Kokelj, 2009). These points are well confirmed by strong inter-station

15 correlations for the selected temperature records for all months (Supplementary Figs. 5-7), and

16 weak inter-station correlations for total precipitation for most months (Supplementary Fig. 8). As

17 such, the total precipitation composites may be less representative of the region compared to the

18 temperature composites. Therefore, correlations between the tree-ring and total precipitation data

19 should be interpreted with caution.

\section{Results and Discussion}

22 Regional growth patterns and divergence 
Tree-ring series from the network span the period AD 1060-2007 (Table 1). More than

$270 \%$ of the sites yielded samples that extend into the $16^{\text {th }}$ century, more than $40 \%$ extend into the

$315^{\text {th }}$ century, and just over $20 \%$ extend into the $14^{\text {th }}$ century or earlier. The oldest samples are

4 from the upland sites ESK, CDU, CDU1, and CDU2, which extend into the $11^{\text {th }}$ or $12^{\text {th }}$ centuries.

5 All sites share a large amount of common variability suggesting a regional growth-limiting factor

6 such as climate. This is demonstrated by a comparison of each site chronology against a regional

7 mean defined by the remaining trees from the network (Fig. 2). Each site is well correlated with

8 its corresponding regional mean. The most strongly correlated sites (e.g., DW, BB, MP, M, FT,

$9 \mathrm{KC} 2$ and SC1) are delta plain sites. Nevertheless, most upland sites (e.g., ESK, NL1, CDU and

10 CDU2) are also well correlated regionally.

11 All tree indices were averaged into a mean chronology (Fig. 3a; hereafter the Mackenzie

12 Delta Regional Chronology or MDRC) to isolate the regional growth pattern and assess its

13 climate response. The MDRC was calculated for the period AD 1245-2007 only, defined by an

14 Expressed Population Signal (EPS; Wigley et al., 1984) above 0.7 (i.e., $70 \%$ signal, $30 \%$ noise),

15 except during the five years AD 1399 and 1405-1408 when EPS is 0.66-0.69. A 51-year window

16 was used to calculate the EPS. The EPS statistic is commonly used in dendroclimatology studies

17 as a measure of the common tree growth pattern in the mean chronology. An EPS of 0.85 is often

18 adopted as a threshold below which the chronology may be less reliable (Wigley et al., 1984),

19 but it is a subjective threshold. The more liberal EPS value of 0.7 is used to facilitate a longer

20 interpretation of the MDRC (n.b., the point in time when EPS exceeds 0.85 is also noted in Fig.

$213 a$ ), and we show towards the end of this paper that early portions of the chronology defined by

22 EPS values between 0.7-0.85 contain valuable climatic information that corresponds with other

23 paleoclimate reconstructions. EPS drops well below 0.5 prior to AD 1245 due to the low number 
1 of samples ( $\leq 15$ trees). The MDRC was not weighted by site, but a site-weighted MDRC is

2 virtually identical to the un-weighted MDRC ( $A D$ 1245-2007, $r=0.97, p \leq 0.001$ ).

The strong regional growth coherence indicates a regional forcing such as climate, but

4 does not necessarily imply that the average tree's response to any specific forcing has been time-

5 stable. The MDRC emulates the divergent growth pattern reported by Pisaric et al. (2007) in the

6 Mackenzie Delta. Pisaric et al. (2007) showed that most, though not all, trees in the delta were

7 susceptible to temperature-growth divergence, and that this divergence began earlier than in most

8 other regions of NWNA. Pisaric et al. (2007) demonstrated that the mean growth patterns of the

9 divergent and divergence-free populations were indistinguishable prior to ca. AD 1900 and very

10 different since then. Comparisons against reconstructed hemispheric-scale temperatures confirm

11 that divergent and divergence-free trees shared a positive temperature response prior to AD 1900

12 (Porter and Pisaric, 2011). Since AD 1900, divergent and divergence-free trees show contrasting

13 low frequency growth patterns, divergence-free trees with a positive temperature response over

14 the $20^{\text {th }}$ century, and divergent trees with a transient temperature response (Pisaric et al., 2007).

15 We reiterate this last point with a comparison of the MDRC against a well-verified ring-

16 width-based June-July temperature reconstruction (AD 1638-1988) by Szeicz and MacDonald

17 (1995) from a network of five high-elevation white spruce sites in the middle-Mackenzie Valley,

18 and parts of central and northern Yukon (all within $500 \mathrm{~km}$ of the Mackenzie Delta; Fig. 1). This

19 comparison (Fig. 3b) shows that the average Mackenzie Delta tree was coupled to reconstructed

20 June-July temperatures from AD 1638-1900 $(\mathrm{r}=0.61, \mathrm{p} \leq 0.01)$. However, there is a clear loss of

21 temperature sensitivity, at least at lower-frequencies, since AD 1900 (AD 1900-1988, $r=0.00$,

22 n.s.; Fig. 3b). This temperature-growth divergence begins roughly a half century before it occurs

23 in most other parts of NWNA (D'Arrigo et al., 2008; Porter and Pisaric, 2011). This same result 
1 is observed when the MDRC is compared with Northern Hemisphere reconstructed temperatures

2 (AD 1600-1900, $r=0.30, p \leq 0.01 ;$ AD 1900-2000, $r=0.09$, n.s.; Fig. 3c), in spite of the large

3 spatial-scale differences.

$4 \quad$ A unique feature of divergence in the Mackenzie Delta is that it occurs in two phases.

5 The first phase spans ca. AD 1900-1950 when tree growth overestimates summer temperatures,

6 and the second phase follows when tree growth underestimates temperatures (Figs. 3b). The first

7 phase is uncommon in NWNA, but the second phase is common (Porter and Pisaric, 2011). The

8 observation that many sites in NWNA responded negatively to late $20^{\text {th }}$-century temperatures, a

9 period of exceptional warmth in recent millennia (Kaufman et al., 2009), has led some to suggest

10 that this response may be linked to warming-induced drought stress (McGuire et al., 2010; Porter

11 and Pisaric, 2011) or a physiological stress due to temperature threshold exceedance (D'Arrigo et

12 al., 2004; Wilmking et al., 2004). However, the first phase of divergence in the Mackenzie Delta,

13 a period of accelerated growth, is clearly a response to favourable not stressful conditions.

14 The strong coherence between our tree-ring network and the Szeicz and MacDonald

15 (1995) network prior to AD 1900 reflects the fact that both are based on white spruce and both

16 experienced similar temperature histories, given their proximity. However, the lack of coherence

17 during the early $20^{\text {th }}$ century suggests that climate-environment feedbacks may influence growth

18 differently across this range of environments. Elevation is a notable difference. The Szeicz and

19 MacDonald (1995) trees are from high-elevation mountain sites while most of our trees are from

20 low-lying delta plain sites. A simple comparison between a mean chronology representing our

21 five upland sites and the Szeicz and MacDonald (1995) reconstruction reveals that the early $20^{\text {th }}$ -

22 century growth surge is unique to delta plain trees (Fig. 3d), implying that conditions unique to

23 the delta plain are responsible for the anomalous early $20^{\text {th }}$-century growth surge. 
One potential factor contributing to the growth surge in the Mackenzie Delta is a release

2 of water and nutrients from near-surface permafrost due to active layer thickening. Trees in the

3 Mackenzie Delta grow on fine-grained alluvial soils underlain by an aggrading permafrost table

4 that traps ice-lenses (Kokelj and Burn, 2005a) and dissolved cations $\left(\mathrm{Ca}^{2+}\right.$ and $\mathrm{Mg}^{2+} ; \mathrm{Kokelj}$ and

5 Burn, 2005b) in near-surface permafrost. Little Ice Age conditions are probably associated with

6 colder permafrost (Kokelj et al., 2007) and a thinner active layer. Warming following the Little

7 Ice Age may have caused the active layer thickness to increase, with air temperatures reaching a

8 local maximum in the 1940s (Burn and Kokelj, 2009), potentially releasing water and nutrients

9 that had accumulated over previous centuries in a relatively short period of time, and resulting in

10 augmented growth. Following this warming, mean annual air temperatures cooled into the 1970s,

11 and later increased to record high levels by the late $20^{\text {th }}$ century (Burn and Kokelj, 2009). While

12 trees at alluvial sites experience water and nutrient additions following flooding, and increases in

13 active layer thickness and rooting depth, upland trees at Campbell Dolomite Upland, which grow

14 in thin soils on bedrock, would not benefit from an increase in active layer thickness, which may

15 explain why they did not experience the early $20^{\text {th }}$-century growth surge.

16 If the early $20^{\text {th }}$-century growth surge is linked to an increase in active layer thickness,

17 then a more pronounced growth trend might have been expected in the late $20^{\text {th }}$ century when air

18 temperatures were higher and further active layer thickening occurred (Burn and Kokelj, 2009).

19 However, the late $20^{\text {th }}$ century is a period of subdued growth for many white spruce stands across

20 NWNA, including the Mackenzie Delta, and the large-scale factors responsible for the depressed

21 growth (e.g., warming-related stress; Barber et al., 2000; D’Arrigo et al., 2004; Lloyd and Bunn,

22 2007; McGuire et al., 2010) may have countered some of the benefit of an increased active layer

23 thickness in the late $20^{\text {th }}$ century. 
3 Since the first point of divergence (ca. AD 1900), the MDRC expressed a strong positive

4 growth trend to record high index values in the AD 1930s, then a negative trend to low values in

5 the AD 1980s, and then a positive trend to higher values at the time of sampling (Fig. 3a). This

6 low-frequency pattern is inconsistent with local instrumental climate data. A correlation analysis

7 between the MDRC and instrumental temperatures (AD 1892-2007) and total precipitation (AD

8 1926-2007) finds no significant correlations except a weak inverse correlation with December

9 precipitation (Table 2). This result is not surprising given the evidence for a transient response to

10 climate since AD 1900, discussed above. Time-dependent correlations between unfiltered tree-

11 ring and climate series have been used to detect transient responses (e.g., D'Arrigo et al., 2004).

12 However, these raw moving correlation analyses are unable to assess the frequency-dependence

13 of the transient response. It is difficult to draw conclusions on lower-frequency climate-growth

14 correlations (e.g., by low-pass filtering the climate and tree-ring series) when only short climate

15 series (e.g., < 100 years) are available, as the effective degrees of freedom are severely reduced

16 with autocorrelation (Wigley et al., 1987). However, high-frequency correlations are not prone to

17 this effect.

A correlation analysis based on first-differenced data (i.e., high-frequency only) shows

19 that the average tree had a significant, positive correlation with June and July temperatures over

20 the $20^{\text {th }}$ century (see ' $1{ }^{\text {st }}$ diff.', Table 2 ). First-difference correlations are strongest for minimum

21 and mean temperatures, and slightly weaker for maximum temperatures. A comparison of first-

22 differenced June-July mean temperatures and ring-width for AD 1911-2007 (Fig. 3e) shows that

23 the relation was stable over the $20^{\text {th }}$ century (n.b., first-differenced June-July temperatures were 
1 not available before AD 1911). This point is supported by similar inter-series correlations for the

2 first $(\mathrm{AD} 1911-1959, \mathrm{r}=0.57, \mathrm{p} \leq 0.01)$ and second $(\mathrm{AD} 1960-2007, \mathrm{r}=0.47, \mathrm{p} \leq 0.01)$ halves

3 of the comparison period. The overall correlation is $r=0.53(p \leq 0.01)$, a level of agreement that

4 is typical for some Alaskan white spruce (Andreu-Hayles et al., 2011). Results from a sign-test

5 also indicate a strong coupling between the two variables $(65+/ 31-, \mathrm{p} \leq 0.01)$.

6 The results presented thus far suggest that divergence in the Mackenzie Delta is mostly

7 restricted to the low-frequency domain and post-AD 1900. However, as was demonstrated by

8 Pisaric et al. (2007), and as we will show next, not all trees from a given site were affected by

9 divergence, and this provides an opportunity to develop a divergence-free regional chronology

10 that can be used to reconstruct past temperatures.

12 Divergence-free regional chronology

13 Large-scale (e.g., hemispheric) climate-proxy reconstructions are often developed from

14 extensive networks of site chronologies that are well correlated and have a time-stable relation

15 with the target climate variable (Briffa et al., 2002; D’Arrigo et al., 2006). In some high-latitude

16 regions, ring-width-based temperature reconstructions have been most successful when tree-ring

17 records were screened for divergence (Wilson et al., 2007). Here, we apply the same principles

18 on our tree-ring network to develop a divergence-free regional chronology. However, rather than

19 excluding divergent series altogether, we exclude only the divergent portions of these series (i.e.,

20 post-AD 1900) as the pre-divergence portions are not in question based on prior analyses and our 21 discussion above.

22 Divergent and divergence-free records can be separated based on their correlation with

23 summer temperature, but as Esper and Frank (2009) suggest, this approach is circular and would 
1 surely lead to a mean chronology that is tuned to the temperature index used in the correlation

2 analysis. Alternatively, growth-trend (positive vs. negative) could be used as a sorting criterion.

3 At the NWNA-scale, Porter and Pisaric (2011) found that most divergent and divergence-free

4 records have consistent growth trends, with respect to sign, over all periods except ca. AD 1950-

5 1980. During the AD 1950-1980 period, divergent records have a negative growth trend while

6 divergence-free trees have a positive trend. However, in areas such as Old Crow Flats (Porter

7 and Pisaric, 2011) and the Mackenzie Delta (Pisaric et al., 2007) the period of contrasting growth

8 trends begins slightly earlier, ca. AD 1930-1980.

$9 \quad$ We examined all 1286 tree indices from the 29 sites and sorted them based on growth 10 trend from AD 1930-1980. Trees with a negative trend were sorted as 'Group 1', and trees with a 11 positive trend were sorted as 'Group 2'. The Group 1 and Group 2 trees were then averaged into 12 regional chronologies (Figs. $4 \mathrm{a}$ and $4 \mathrm{~b}$ ). The regional chronologies are only given for years with 13 an EPS above 0.7 (EPS $\geq 0.85$ is also noted in Fig. 4), as was done for the MDRC. Ring-width 14 series from deadwood that did not cover the AD 1930-1980 period were left unsorted and were 15 averaged into a 'Snag' regional chronology (Fig. 4c).

16 Of the sorted trees, most are Group 1 (Table 3). Three sites did not contain any Group 2 17 trees (FT, AK1, and AK2). Of the 26 sites that had both responses, the majority of trees (82\% for 18 the average site) were Group 1. The dominance of Group 1 trees was observed at all sites except 19 ESK and CDU1. Group 2 trees represent $20-30 \%$ of the population at some sites including NL1, $20 \mathrm{CDU} 2, \mathrm{TM}, \mathrm{MS}, \mathrm{HL}, \mathrm{AC} 1, \mathrm{NC} 2, \mathrm{KC} 1$, and $\mathrm{WC} 1$. Regionally, there is no statistical difference in 21 mean series length between Group 1 and Group 2 trees ( 261 vs. 263 years; $1 \sigma=76$ vs. 79 years),

22 suggesting that the contrasting growth responses are not a function of age. Rather, they are more 23 likely due to differences in local factors (King, 2009; Porter and Pisaric, 2011). 
A comparison of the regionally averaged Group 1, Group 2 and Snag chronologies shows

2 that all trees, regardless of grouping, shared a common growth pattern from AD 1644 until 1900

3 (Fig. 4d). The mean inter-series correlation between the three chronologies during this period is

$4 \quad 0.87(\mathrm{p} \leq 0.001)$. After AD 1900, Group 1 trees had a sharp upward trend to ca. AD 1930, then a

5 decline to ca. AD 1980. As would be expected, the Snag chronology closely follows the Group 1

6 chronology post-AD 1900 as it is an unsorted chronology and is defined mostly by Group 1 trees

7 which dominate regionally. Conversely, Group 2 trees had a positive trend since AD 1900.

8 To demonstrate that the contrasting growth patterns post-1900 are not an artefact of the

9 detrending method, the raw series belonging to each group were re-standardised and compared

10 using three other methods: traditional negative-exponential/negative-to-zero-slope linear (Fig.

11 5a); horizontal line equal to series mean (Fig. 5b); and regional curve standardisation (Fig. 5c).

12 Regional curve standardisation (Briffa et al., 1990) was applied on a site-by-site basis, as growth

13 rate varies between sites and, therefore, a single regional curve is not appropriate for all trees in

14 the region (Briffa and Melvin, 2011). Each method demonstrates the same post-1900 differences

15 between Group 1 and Group 2 trees, suggesting these contrasting patterns are not artefacts of the

16 curve fitting method chosen. The comparison of the 'horizontal line' chronologies is particularly

17 informative, as it reflects raw growth variability (i.e., climate- and age-driven trends), unaltered

18 by curve fitting. Another notable point is that there seems to be little if any loss of long-timescale

19 variance from use of data-adaptive curve standardisation, based on the similarity of chronologies

20 produced by regional curve and negative-exponential standardisation methods. Regional curve

21 standardisation is generally considered superior in ability to retain long-timescale variance.

A running standard deviation of all ring-width indices (Fig. 4e) was calculated as further

23 evidence that all trees, regardless of grouping, had similar growth patterns before AD 1900, but 
1 increasingly variable growth patterns since. The regional standard deviation was relatively stable

2 during AD 1245-1900, with smoothed (41-year cubic smoothing spline, 50\% frequency cut-off;

3 Cook and Peters, 1981) values ranging from 0.30-0.47 (mean = 0.37). Subsequently, the regional

4 standard deviation increases sharply to a local maximum of ca. 0.66 in the AD 1930s, a period

5 when the Group 1 and Group 2 trees show considerable differences. During the mid-20 ${ }^{\text {th }}$ century,

6 the regional standard deviation returns to pre-AD 1900 levels, since Group 1 and Group 2 indices

7 are similar in value as they cross each other trending in opposite directions. Finally, the regional

8 standard deviation increases sharply to end the record above 1.0, indicating that ring-width

9 indices across the region are most variable during the late $20^{\text {th }}$ century. Again, these differences

10 are evident between the Group 1 and Group 2 regional chronologies (Fig. 4d).

12 Calibration and verification

13 Based on the premise that temperature-growth divergence is restricted to the $20^{\text {th }}$ century

14 (Cook et al., 2004; Porter and Pisaric, 2011), we calculated a Divergence-Free Regional

15 Chronology (DFRC) from the robust bi-weight mean of all ring-width indices before AD 1900

16 and only Group 2 indices since AD 1900, thereby excluding divergent signals. As was the case

17 for the other chronologies presented thus far, the DFRC is defined by an EPS above 0.7.

18 The DFRC was correlated with the regional climate data to determine its optimal climate

19 response (Table 2). The strongest and most significant correlations were observed for June and

20 July minimum and mean temperatures, as noted earlier for the 'all trees' first-differenced data

21 (n.b., Group 2 trees that define the modern portion of the DFRC have the same high-frequency

22 growth pattern as 'all trees' - Supplementary Fig. 9). The finding that June and July minimum 
1 and mean temperatures are well correlated with tree growth at both high- and low-frequencies

2 provides some confidence that these relations are not spurious.

3 June-July (and June-August) is a common season of influence for temperature-sensitive

4 chronologies from high-latitude and -elevational sites in North America and Eurasia (Szeicz and

5 MacDonald, 1995; Gostev et al., 1996; Büntgen et al., 2005; Wilson et al., 2007; Youngblut and

6 Luckman, 2008; D'Arrigo et al., 2009; Esper et al., 2010; Porter and Pisaric, 2011; Flower and

7 Smith, 2012). However, few studies have explored correlations with minimum (night time) and

8 maximum (day time) temperatures. Rather, most studies focus on mean temperature only. Here,

9 we find notable differences between minimum, mean, and maximum temperature correlations.

10 The June correlation is similar between minimum $(\mathrm{r}=0.56, \mathrm{p} \leq 0.01)$ and mean $(\mathrm{r}=0.51, \mathrm{p} \leq$

11 0.01) temperatures, but the July correlation is much stronger for minimum $(r=0.43, p \leq 0.01)$

12 versus mean $(r=0.23, p \leq 0.01)$ temperatures. Wilson and Luckman (2003; also Luckman and

13 Wilson, 2005; Youngblut and Luckman, 2008) showed that maximum temperatures are more

14 closely correlated with tree growth in some environments. Wilson and Luckman (2003) suggest

15 this may be due to the fact that most photosynthesis occurs during the day time and, presumably,

16 day time temperatures are more likely to influence photosynthesis. However, we find the DFRC

17 is more closely associated with June-July minimum temperatures $(r=0.60, p \leq 0.01)$ compared

18 mean or maximum temperatures $(r=0.46$ and 0.31 , respectively, $\mathrm{p} \leq 0.01)$. This sensitivity may

19 reflect the fact that early June minimum temperatures in the region can approach the freezing

20 point and, therefore, can also significantly limit biological activity and growth.

21 Based on our correlation analysis, June-July minimum temperature is the optimal climate

22 index for the DFRC. Standard split-period calibration-verification testing (Cook and Kairiukstis,

23 1990) was used to evaluate the robustness of the DFRC-temperature relation. Two 53-year 
1 calibration periods were defined: AD 1893-1954 (Split 1) and 1955-2007 (Split 2). The Split 1

2 calibration period spans 62 calendar years, but contains only 53 years of June-July temperature

3 measurements due to discontinuities in the regional temperature record (Supplementary Fig. 5).

4 Also, 3 of the 53 years (AD 1893, 1900, and 1908) in Split 1 contain measurements for June but

5 not July, and 2 of the 53 years (AD 1895 and 1896) contain measurements for July but not June.

6 In order to calculate June-July averages for these years, the missing June or July values were

7 estimated from the average of the 4 closest years of data.

8 For each calibration period, the DFRC and the June-July minimum temperature records

9 were compared and the following statistics were calculated to evaluate the relation: Pearson's

10 Product Moment Correlation Coefficient (r), coefficient of determination $\left(\mathrm{r}^{2}\right)$, adjusted $\mathrm{r}^{2}$,

11 standard error of the estimate (SE), Durbin-Watson (DW), and sign-test. Calibration models

12 were verified over the years that were excluded from the calibration periods. The following

13 statistics were calculated for each verification period to evaluate the stability of the calibration

14 relations: Pearson's r, Reduction of Error (RE), and Coefficient of Efficiency (CE).

15 Modelled temperatures explain 18\% and 23\% (adjusted $\mathrm{r}^{2}$ ) of observed temperatures for

16 Splits 1 and 2, and 35\% for the full period model (Table 4). Values in this range are typical of

17 high-latitude ring-width networks which express temperature signals best at lower frequencies

18 (Cook et al., 2004; D'Arrigo et al., 2006). As expected, the explained variance of the full period

19 model increases with smoothing (e.g., adjusted $\mathrm{r}^{2}=0.66$ for the period AD 1910-2007 if a 9-year

20 cubic smoothing spline is used). For Splits 1 and 2, and the full period model, the DW statistic is

21 always close to a value of 2.0 indicating low residual autocorrelation, and the SE has a narrow

22 range from $0.81-0.88$ suggesting the magnitude of unexplained variance is stationary. The Split 1

23 and full period calibration models pass a sign-test at the 95\% confidence level, but Split 2 does 
1 not. Despite the weaker Split 2 sign-test result, the overall result is encouraging given the lower-

2 frequency nature of temperature signals in high-latitude tree growth and implies that some inter-

3 annual temperature variability is preserved in the rings. This last point is also confirmed by the

4 comparison of first-differenced ring-width and temperature data (Fig. 3e).

5 The verification statistics indicate that the calibrations are robust and time-stable (Table

6 4). The most informative statistics are the RE and CE which are always above zero, except the

7 CE of Split 1. By definition, any model with an RE or CE above zero demonstrates some skill

8 and is predictively superior to a model defined by the mean climatologies of the calibration (RE)

9 and verification (CE) periods. Based on the RE results alone, the calibration models are skilful.

11 Temperature reconstruction, $A D$ 1245-2007

12 The DFRC passes most of the standard calibration-verification tests, suggesting it can be

13 used as a proxy for June-July minimum temperatures. The full-period model (Table 4) was used

14 to reconstruct June-July minimum temperatures since AD 1245 (Fig. 6). The $2 \sigma$ confidence

15 interval for the reconstruction is $1.72^{\circ} \mathrm{C}(2 \times \mathrm{SE})$, which does not account for changes in sample

16 depth or model parameter uncertainties. As such, $1.72^{\circ} \mathrm{C}$ probably underestimates the true $2 \sigma$

17 confidence interval.

18 From AD 1910-2007, both reconstructed and observed June-July minimum temperatures

19 had warming trends of $0.2^{\circ} \mathrm{C} /$ decade or a total change of $1.96^{\circ} \mathrm{C}$ (Fig. 6a). Comparatively, mean

20 June-July temperatures for this region increased by only $1.46^{\circ} \mathrm{C}$, which is still more than double

21 the global trend of ca. $0.70^{\circ} \mathrm{C}$ for the same period (Brohan et al., 2006). The Mackenzie Delta

22 and other regions of NWNA have experienced some of the most rapid warming trends in recent 
1 decades (ACIA, 2005), which is partly explained by sea ice losses in the Beaufort and Chukchi

2 Seas (Serreze et al., 2009).

3 Over longer time-scales, the reconstruction indicates that the most recent decade (AD

4 2000-2009) was the warmest on record since $\mathrm{AD} 1245$, and ca. $1.4^{\circ} \mathrm{C}$ warmer than any other

5 decade prior to the mid-20 $0^{\text {th }}$ century (Table 5). Six of the top ten warmest decades are from the

$620^{\text {th }}$ and $21^{\text {st }}$ centuries. The other four warmest decades are the $1520 \mathrm{~s}, 1530 \mathrm{~s}, 1540 \mathrm{~s}$, and $1770 \mathrm{~s}$.

7 Consistent with the IPCC's Fourth Assessment Report, we also find that the most recent 50-year

8 period was the warmest 50-year period in the last 500 years (Jansen et al., 2007), and since AD

91245.

10 Four of the ten coldest decades in our reconstruction span AD 1810-1849 (Table 5),

11 which corresponds with a period of increased volcanism (Gao et al., 2008) and the Dalton solar

12 minimum (Bard et al., 2000). Four of the other six coldest decades span the period AD 1260-

13 1299, again coinciding with increased volcanism (Gao et al., 2008) and the onset of the Wolfe

14 solar minimum, but not its peak (Bard et al., 2000). The other two coldest decades are the 1340s

15 and 1700s, which overlap with the Wolfe and Maunder solar minima, respectively (Bard et al.,

16 2000). It is notable that these cool periods are recorded by other temperature-sensitive tree-ring

17 chronologies in NWNA (Luckman and Wilson, 2005; D'Arrigo et al., 2006; Porter and Pisaric,

18 2011; Anchukaitis et al., 2012), which suggests volcanism and solar output have been important

19 drivers of summer temperature variability before the $20^{\text {th }}$ century. However, recent high-latitude

20 warming is mostly amenable to anthropogenic forcing (IPCC, 2007) and Arctic amplification

21 (Serreze et al., 2009).

22

23 Long-term, regional-scale validation 
Our reconstruction is validated by comparison with several independent temperature

2 proxy records from elsewhere in NWNA (Fig. 1). The Szeicz and MacDonald (1995) June-July

3 temperature reconstruction $(\mathrm{AD} 1638-1988)$ is well correlated $(\mathrm{r}=0.68, \mathrm{p} \leq 0.001)$ with our

4 reconstruction and shares the same low-frequency trends (Fig. 6b). This coherence is mutually

5 corroborative and demonstrates that both tree-ring networks responded to the same regional

6 climate.

7 A tree-ring $\delta^{18} \mathrm{O}$-based reconstruction of April-July minimum temperatures (AD 1780-

8 2003) by Porter et al. (2013; see also Porter et al., 2009) for the Mackenzie Delta also correlates

9 well $(\mathrm{r}=0.49, \mathrm{p} \leq 0.001)$ with our June-July temperature reconstruction (Fig. $6 \mathrm{c})$, in spite of the

10 seasonal differences in temperature signal. This result is especially meaningful because the two

11 temperature signals originate from different processes. The $\delta^{18} \mathrm{O}$-temperature signal derives from

12 temperature-dependent labelling of precipitation isotopes and use of this water during synthesis

13 of cellulose precursors leading to tree-ring formation, whereas the ring-width-temperature signal

14 likely results from several biological processes and phenological constraints that are influenced

15 by temperature. Both records show cool conditions in the early 1800 s and a progressive warming

16 trend into the $20^{\text {th }}$ century.

17 The OCF-Group 2 chronology (AD 1620-2007), from a network of 11 divergence-free

18 white spruce ring-width chronologies from Old Crow Flats, northern Yukon (Fig. 1; Porter and

19 Pisaric, 2011), correlates strongly ( $\mathrm{r}=0.83, \mathrm{p} \leq 0.001)$ with our reconstruction (Fig. 6d). This

20 strong correlation is due to the early summer temperature sensitivity of both tree-ring networks,

21 and the fact that air temperatures between the regions are strongly coupled (Porter and Pisaric,

22 2011). The coherence of the two records over the last four centuries indicates that both regions

23 shared similar temperature histories. 
Finally, the Coppermine River ring-width chronology (AD 1046-2003) by D’Arrigo et al.

2 (2009) from a stand of white spruce in Nunavut, Canada (Fig. 1) is also well correlated (r $=0.44$,

$3 \mathrm{p} \leq 0.001$ ) with our reconstruction (Fig. 6e). The temperature-dependence of this chronology is

4 affirmed by several studies (D’Arrigo et al., 2009; Visser et al., 2010; Porter and Pisaric, 2011).

5 Since AD 1245, the Coppermine chronology has tracked low-frequency trends expressed in our

6 reconstruction, with inter-series coherence being especially strong since AD $1600(\mathrm{r}=0.57, \mathrm{p} \leq$

7 0.01). Reduced coherence before AD 1600 may reflect several factors including lower sample

8 depth, regional temperature differences, or differences in regional-representativeness (e.g., the

9 DFRC represents 29 sites, while the Coppermine chronology represents a single site).

11 Long-term, hemispheric-and circum-Arctic-scale validation

12 Our reconstruction is also well matched by larger-scale temperature reconstructions. A

13 composite of six hemispheric-scale reconstructions (see Supplementary Note 4), largely tree-

14 ring-based and representative of the Northern Hemisphere, was compared to our reconstruction

15 (Fig. 6f). The hemispheric reconstructions were produced mainly from tree-ring data detrended

16 by the regional curve standardisation method (Briffa et al., 1990) which is optimized for low-

17 frequency trends, in comparison to the DFRC reconstruction which was produced from tree-ring

18 data detrended by data-adaptive signal-free standardisation (Melvin and Briffa, 2008). Despite

19 differences in data processing and, especially, spatial-scale, the two records are well correlated (r

$20=0.54, \mathrm{p} \leq 0.001)$ over the last 8 centuries suggesting they are responding to the same climatic

21 variable, i.e., warm-season temperatures. One notable difference occurs in the mid- $20^{\text {th }}$ century

22 when the hemispheric-scale composite indicates pronounced warming, while our reconstruction

23 does not. This mid-20 $0^{\text {th }}$-century warmth (centered around ca. AD 1950) is common feature of 
1 Northern Hemisphere instrumental temperature records (Brohan et al., 2006), but it is much less

2 pronounced in the Mackenzie Delta region (Fig. 6a). Rather, the Mackenzie Delta experienced

3 subdued summer warming in the mid- $20^{\text {th }}$ century followed by recently accelerated warming.

4 Lastly, our reconstruction agrees with a multi-proxy temperature reconstruction based on

5 a network of Arctic sites (Fig. 6g) by Kaufman et al. (2009). The circum-Arctic reconstruction is

6 based on Kaufman et al.'s (2009) ice- and lake-core records only (see Supplementary Note 5).

7 The temporal resolution of the circum-Arctic reconstruction is coarse (10-year) compared to our

8 annual reconstruction, but both records share similar low-frequency trends. Following AD 1245,

9 both records transition from warm to cool conditions by the late $13^{\text {th }}$ century, and then a warming

10 trend to the ca. AD 1500s; although the circum-Arctic record indicates brief cooling at ca. AD

111525 (n.b., this brief cooling is also evident in the 6-study hemispheric comparison - see Fig. 6f).

12 Subsequently, both records exhibit a long-term cooling trend to the early $19^{\text {th }}$ century, followed

13 by strong warming to present. This qualitative agreement suggests the broader circum-Arctic and

14 Mackenzie Delta regions shared similar temperature histories with exceptionally warmth during

15 recent decades.

\section{Concluding remarks}

18 Divergence is a widespread phenomenon in NWNA, including the Mackenzie Delta.

19 Testing of the common growth signal in the study region and standard deviations indicated that

20 divergence did not occur at these sites prior to the $20^{\text {th }}$ century. Furthermore, divergence has not

21 affected all trees, which provides an opportunity to build chronologies that represent a time-

22 stable response to climate if divergent signals are excluded from the regional chronology, as we

23 have demonstrated here. Local-scale factors that moderate growing conditions, such as organic 
1 layer thickness, stand density, and near-surface ground ice, may be particularly important to why

2 some trees diverge and should be evaluated in future studies. Because the factor(s) responsible

3 for divergence remain uncertain, it is important to assess the long-term stability of reconstructed

4 temperatures based on comparisons with independent proxy reconstructions. Such comparisons

5 provide assurances that earlier periods of divergence have not severely biased the reconstruction.

6 Building on previous studies from this region, we provide a greatly expanded network of white

7 spruce sites and a regional perspective on summer temperatures in the Mackenzie Delta region

8 over the last eight centuries that confirms recent decades have been exceptionally warm.

\section{Acknowledgements}

11 We thank A. Burn and G. King for help in the field, and the contributors of secondary

12 tree-ring data used in this study. This paper benefitted from comments by T. Melvin and one

13 anonymous reviewer, and editorial suggestions by P. Bartlein and D. Booth. Comments from B.

14 Luckman on an earlier version of this manuscript are also appreciated. Funding and logistical

15 support is gratefully acknowledged from: Aboriginal Affairs and Northern Development Canada,

16 Cumulative Impact Monitoring Program and Northern Scientific Training Program; Natural

17 Sciences and Engineering Research Council of Canada; and Polar Continental Shelf Program.

18 This paper is NWT Geoscience Office Contribution no. 0070.

\section{References}

21 ACIA, 2005. Arctic Climate Impact Assessment. Cambridge University Press, New York, NY, 22 USA, $1042 \mathrm{pp}$.

23 Anchukaitis, K., D’Arrigo, R., Andreu-Hayles, L., Frank, D., Verstege, A., Curtis, A., Buckley,

24 B., Jacoby, G., Cook, E., 2012. Tree-ring reconstructed summer temperatures from northwestern 
North America during the last nine centuries. Journal of Climate, doi:10.1175/JCLI-D-1100139.1 .

3 Anderson, L., Abbott, M.B., Finney, B.P., Burns, S.J., 2007. Late Holocene moisture balance

4 variability in the southwest Yukon Territory, Canada. Quaternary Science Reviews 26, 130-141.

5 Anderson, L., Finney, B.P., Shapley, M.D., 2011. Lake carbonate- $\delta^{18} \mathrm{O}$ records from the Yukon

6 Territory, Canada: Little Ice Age moisture variability and patterns. Quaternary Science Reviews

$730,887-898$.

8 Andreu-Hayles, L., D’Arrigo, R., Anchukaitis, K.J., Beck, P.S.A., Frank, D., Goetz, S., 2011.

9 Varying boreal forest response to Arctic environmental change at the Firth River, Alaska.

10 Environmental Research Letters 6, doi:10.1088/1748-9326/6/4/045503.

11 Barber, V.A., Juday, G.P., Finney, B.P., 2000. Reduced growth of Alaskan white spruce in the 12 twentieth century from temperature-induced drought stress. Nature 405, 668-673.

13 Bard, E., Raisbeck, G., Yiou, F., Jouzel, J., 2000. Solar irradiance during the last 1200 years 14 based on cosmogenic nuclides. Tellus B 52, 985-992.

15 Bégin, C., Michaud, Y., Archambault, S., 2000. Tree-ring evidence of recent climate changes in 16 the Mackenzie Basin, Northwest Territories. Geological Survey of Canada Bulletin 547, 65-77.

17 Briffa, K.R., Bartholin, T.S., Eckstein, D., Jones, P.D., Karlén, W., Schweingruber, F.H., 18 Zetterberg, P., 1990. A 1,400-year tree-ring record of summer temperatures in Fennoscandia.

19 Nature 346, 434-439.

20 Briffa, K.R., Melvin, T.M., 2011. A closer look at regional curve standardization of tree-ring records: Justification of the need, a warning of some pitfalls, and suggested improvements in its application. In: Hughes, M., Swetnam, T., Diaz, H. (Eds.), Dendroclimatology: Progress and Prospects. Springer, New York, pp. 113-145.

24 Briffa, K.R., Osborn, T.J., Schweingruber, F.H., Jones, P.D., Shiyatov, S.G., Vaganov, E.A., 25 2002. Tree-ring width and density data around the Northern Hemisphere: Part 1, local and 26 regional climate signals. The Holocene 12, 737-757.

27 Brohan, P., Kennedy, J.J., Haris, I., Tett, S.F.B., Jones, P.D., 2006. Uncertainty estimates in 28 regional and global observed temperature changes: A new data set from 1850. Journal of 29 Geophysical Research 111, doi:10.1029/2005JD006548.

30 Bunn, A.G., Goetz, S.J., Kimball, J.S., Zhang, K., 2007. Northern high-latitude ecosystems 31 respond to climate change. EOS Transactions 34, 333-335.

32 Büntgen, U., Esper, J., Frank, D., Nicolussi, K., Schmidhalter, M., 2005. A 1052-year tree-ring 33 proxy for Alpine summer temperatures. Climate Dynamics 25, 141-153. 
1 Burn, C.R., Kokelj, S. V, 2009. The environment and permafrost of the Mackenzie Delta area.

2 Permafrost and Periglacial Processes 20, 83-105.

3 Cook, E.R., 1985. A Time Series Analysis Approach to Tree Ring Standardization. PhD

4 dissertation. University of Arizona, Tuscon, USA, $171 \mathrm{pp}$.

5 Cook, E.R., Briffa, K.R., Meko, D.M., Graybill, D.A., Funkhouser, G., 1995. The "segment

6 length curse" in long tree-ring chronology development for paleoclimatic studies. The Holocene

$7 \quad 5,229-237$.

8 Cook, E.R., Esper, J., D’Arrigo, R.D., 2004. Extra-tropical Northern Hemisphere land

9 temperature variability over the past 1000 years. Quaternary Science Reviews 23, 2063-2074.

10 Cook, E.R., Kairiukstis, L.A., 1990. Methods of Dendrochronology: Applications in the

11 Environmental Sciences. Kluwer Academic Publishers, Boston, 394 pp.

12 Cook, E.R., Peters, K., 1981. The smoothing spline: a new approach to standardizing forest

13 interior tree-ring width series for dendroclimatic studies. Tree-Ring Bulletin 41, 45-53.

14 D’Arrigo, R., Jacoby, G., Buckley, B., Sakulich, J., Frank, D., Wilson, R., Curtis, A.,

15 Anchukaitis, K., 2009. Tree growth and inferred temperature variability at the North American

16 arctic treeline. Global and Planetary Change 65, 71-82.

17 D’Arrigo, R., Kaufmann, R.K., Davi, N., Jacoby, G.C., Laskowski, C., Myneni, R.B., Cherubini, 18 P., 2004. Thresholds for warming-induced growth decline at elevational tree line in the Yukon

19 Territory, Canada. Global Biogeochemical Cycles 18, doi:10.1029/2004GB002249.

20 D'Arrigo, R., Wilson, R., Jacoby, G., 2006. On the long-term context for late twentieth century 21 warming. Journal of Geophysical Research 111, doi:10.1029/2005JD006352.

22 D'Arrigo, R., Wilson, R., Liepert, B., Cherubini, P., 2008. On the "Divergence Problem" in 23 northern forests: A review of the tree-ring evidence and possible causes. Global and Planetary

24 Change 60, 289-305.

25 Drobyshev, I., Simard, M., Bergeron, Y., Hofgaard, A., 2010. Does soil organic layer thickness

26 affect climate-growth relationships in the black spruce boreal ecosystem? Ecosystems 13, 55627574.

28 Dyke, A.S., Andrews, J.T., Clark, P.U., England, J.H., Miller, G.H., Shaw, J., Veillette, J.J., 29 2002. The Laurentide and Innuitian ice sheets during the Last Glacial Maximum. Quaternary

30 Science Reviews 21, 9-31.

31 Esper, J., Cook, E.R., Schweingruber, F.H., 2002. Low-frequency signals in long tree-ring 32 chronologies for reconstructing past temperature variability. Science 295, 2250-2253. 
1 Esper, J., Frank, D., 2009. Divergence pitfalls in tree-ring research. Climatic Change 94, 2612266.

3 Esper, J., Frank, D., Büntgen, U., Verstege, A., Hantemirov, R.M., Kirdyanov, A.V., 2010.

4 Trends and uncertainties in Siberian indicators of 20th century warming. Global Change Biology $5 \quad 16,386-398$.

Flower, A., Smith, D.J., 2012. A dendroclimatic reconstruction of June-July mean temperature in the northern Canadian Rocky Mountains. Dendrochronologia 29, 55-63.

8 Frank, D., Esper, J., Cook, E.R., 2007. Adjustment for proxy number and coherence in a large-

9 scale temperature reconstruction. Journal of Geophysical Research 34,

10 doi:10.1029/2007GL030571.

11 Fritts, H.C., Moismann, J.E., Bottorff, C.P., 1969. A revised computer program for standardizing 12 tree-ring series. Tree-Ring Bulletin 29, 15-20.

13 Gao, C., Robock, A., Ammann, C., 2008. Volcanic forcing of climate over the past 1500 years:

14 An improved ice core-based index for climate models. Journal of Geophysical Research 113, 15 doi:10.1029/2008JD010239.

Gostev, M., Wiles, G., D’Arrigo, R., Jacoby, G., Khomentovsky, P., 1996. Early summer temperatures since 1670 A.D. for Central Kamchatka reconstructed based on a Siberian larch tree-ring width chronology. Canadian Journal of Forest Research 26, 2048-2052.

19 Holmes, R.L., 1983. Computer-assisted quality control in tree-ring dating and measurement.

20 Tree-Ring Bulletin 43, 69-78.

21 Hughes, M.K., 2011. Dendroclimatology in high-resolution paleoclimatology. In: Hughes, M.K., 22 Swetnam, T.W., Diaz, H.F. (Eds.), Dendroclimatology: Progress and Prospects. Springer, New

23 York, pp. 17-34.

24 IPCC, 2007. Climate Change 2007: The Physical Science Basis, Contribution of Working Group 25 I to the Fourth Assessment Report of the Intergovernmental Panel on Climate Change.

26 Cambridge University Press, New York, NY, USA, 996 pp.

27 Jacoby, G.C., D'Arrigo, R.D., 1995. Tree ring width and density evidence of climatic and

28 potential forest change in Alaska. Global Biogeochemical Cycles 9, 227-234.

29 Jansen, E., Overpeck, J., Briffa, K.R., Duplessy, J.C., Joos, F., Masson-Delmotte, V., Olago, D., 30 Otto-Bliesner, B., Peltier, W.R., Rahmstorf, S., Ramesh, R., Raynaud, D., Rind, D., Solomina, 31 O., Villalba, R., Zhang, D., Jensen, E.J., 2007. Palaeoclimate. In: Solomon, S., Qin, D., 32 Manning, M., Chen, Z., Marquis, M., Averyt, K.B., Tignor, M., Miller, H.L. (Eds.), Climate 33 Change 2007: The Physical Science Basis, Contribution of Working Group I to the Fourth 34 Assessment Report of the Intergovernmental Panel on Climate Change. Cambridge University 35 Press, Cambridge, United Kingdom and New York, USA, pp. 433-497. 
Kaufman, D.S., Schneider, D.P., McKay, N.P., Ammann, C.M., Bradley, R.S., Briffa, K.R., Miller, G.H., Otto-Bliesner, B.L., Overpeck, J.T., Vinther, B.M., and Arctic Lakes 2k Project Members, 2009. Recent warming reverses long-term Arctic cooling. Science 325, 1236-1239. Mackenzie Delta, NT. Unpublished MSc thesis. Carleton University, Ottawa, Canada, 159 pp. Inuvik, Northwest Territories, Canada. Permafrost and Periglacial Processes 14, 275-289.

8 Kokelj, S. V, Burn, C.R., 2005a. Near-surface ground ice in sediments of the Mackenzie Delta, 9 Northwest Territories, Canada. Permafrost and Periglacial Processes 16, 291-303.

10 Kokelj, S. V, Burn, C.R., 2005b. Geochemistry of the active layer and near-surface permafrost, 11 Mackenzie delta region, Northwest Territories, Canada. Canadian Journal of Earth Sciences 42, $12 \quad 37-48$.

13 Kokelj, S. V, Pisaric, M.F.J., Burn, C.R., 2007. Cessation of ice wedge development during the 14 20th century in spruce forests of eastern Mackenzie Delta, Northwest Territories, Canada.

15 Canadian Journal of Earth Sciences 44, 1503-1515.

Lantz, T.C., Marsh, P., Kokelj, S. V, 2012. Recent shrub proliferation in the Mackenzie Delta uplands and microclimatic implications. Ecosystems , doi:10.1007/s10021-012-9595-2.

18 Lawrimore, J.H., Menne, M.J., Gleason, B.E., Williams, C.N., Wuertz, D.B., Vose, R.S., Rennie, 19 J., 2011. An overview of the Global Historical Climatology Network monthly mean temperature 20 data set, Version 3. Journal of Geophysical Research 116, doi:10.1029/2011JD016187.

21 Lloyd, A.H., Bunn, A.G., 2007. Responses of the circumpolar boreal forest to 20th century 22 climate variability. Environmental Research Letters 2, doi:10.1088/1748-9326/2/4/045013.

23 Lloyd, A.H., Fastie, C.L., 2002. Spatial and temporal variability in the growth and climate 24 response of treeline trees in Alaska. Climatic Change 52, 481-509.

25 Luckman, B.H., Wilson, R.J.S., 2005. Summer temperatures in the Canadian Rockies during the 26 last millennium: A revised record. Climate Dynamics 24, 131-144.

27 Mackay, J.R., 1963. The Mackenzie Delta area, N.W.T. Geographical Branch Memoir.

28 Department of Mines and Technical Surveys, Ottawa, Ontario, pp. 202.

McGuire, A.D., Ruess, R.W., Lloyd, A., Yarie, J., Clein, J.S., Juday, G.P., 2010. Vulnerability of white spruce tree growth in interior Alaska in response to climate variability:

31 Dendrochronological, demographic, and experimental perspectives. Canadian Journal of Forest 32 Research 40, 1197-1209. 
Melvin, T.M., Briffa, K.R., 2008. A "signal-free" approach to dendroclimatic standardisation.

2 Dendrochronologia 26, 71-86.

3 Nguyen, T.N., Burn, C.R., King, D.J., Smith, S.L., 2009. Estimating the extent of near-surface

4 permafrost using remote sensing, Mackenzie Delta, Northwest Territories. Permafrost and

5 Periglacial Processes 20, 141-153.

Norris, D.K., 1981. Aklavik, District of Mackenzie. Geology Map 1517A (1:250,000).

7 Geological Survey of Canada, Ottawa, Canada.

8 Pearce, C.M., McLennan, D., Cordes, L.D., 1988. The evolution and maintenance of white 9 spruce woodlands on the Mackenzie Delta, N.W.T., Canada. Holarctic Ecology 11, 248-258.

10 Pisaric, M.F.J., Carey, S.K., Kokelj, S. V, Youngblut, D., 2007. Anomalous 20th century tree 11 growth, Mackenzie Delta, Northwest Territories, Canada. Geophysical Research Letters 34, 12 doi:10.1029/2006GL029139.

13 Porter, T.J., Pisaric, M.F.J., 2011. Temperature-growth divergence in white spruce forests of Old 14 Crow Flats, Yukon Territory, and adjacent regions of northwestern North America. Global 15 Change Biology 17, 3418-3430.

Porter, T.J., Pisaric, M.F.J., Field, R.D., Kokelj, S. V, Edwards, T.W.D., DeMontigny, P., Healy, R., LeGrande, A.N., 2013. Spring-summer temperatures since AD 1780 reconstructed from stable oxygen isotope ratios in white spruce tree-rings from the Mackenzie Delta, northwestern Canada. Climate Dynamics, doi:10.1007/s00382-013-1674-3.

Porter, T.J., Pisaric, M.F.J., Kokelj, S. V, Edwards, T.W.D., 2009. Climatic signals in $\delta^{13} \mathrm{C}$ and $\delta^{18} \mathrm{O}$ of tree-rings from white spruce in the Mackenzie Delta region, northern Canada. Arctic,

22 Antarctic, and Alpine Research 41, 497-505.

23 Rampton, V.N., 1988. Quaternary Geology of the Tuktoyaktuk Coastlands, Northwest

24 Territories. Memoir 423 Geological Survey of Canada, Ottawa, Canada.

25 Serreze, M.C., Barrett, A.P., Stroeve, J.C., Kindig, D.N., Holland, M.M., 2009. The emergence 26 of surface-based Arctic amplification. The Cryosphere 3, 11-19.

27 Speer, J.H., 2010. Fundamentals of Tree-Ring Research. University of Arizona Press, Tucson, 28 Arizona, $252 \mathrm{pp}$.

29 Szeicz, J.M., MacDonald, G.M., 1995. Dendroclimatic reconstruction of summer temperatures in 30 northwestern Canada since A.D. 1638 based on age-dependent modelling. Quaternary Research $3144,257-266$.

32 Szeicz, J.M., MacDonald, G.M., 1996. A 930-year ring-width chronology from moisture-

33 sensitive white spruce (Picea glauca Moench) in northwestern Canada. The Holocene 6, 34534351. 
Tape, K., Sturm, M., Racine, C., 2006. The evidence for shrub expansion in northern Alaska and the Pan-Arctic. Global Change Biology 12, 686-702.

Turetsky, M.R., Kane, E.S., Harden, J.W., Ottmar, R.D., Manies, K.L., Hoy, E., Kasischke, E.S., 2011. Recent acceleration of biomass burning and carbon losses in Alaskan forests and peatlands. Nature Geoscience 4, 27-31.

Visser, H., Büntgen, U., D’Arrigo, R., Petersen, A.C., 2010. Detecting instabilities in tree-ring proxy calibration. Climate of the Past Discussions 6, 225-255.

8 Walker, D.A., Raynolds, M.K., Daniëls, F.J.A., Einarsson, E., Elvebakk, A., Gould, W.A., 9 Katenin, A.E., Kholod, S.S., Markon, C.J., Melnikov, E.S., Moskalenko, N.G., Talbot, S.S., and the other members of the CAVM Team, 2005. The Circumpolar Arctic vegetation map. Journal of Vegetation Science 16, 267-282.

12 Wigley, T.M.L., Briffa, K.R., Jones, P.D., 1984. On the average value of correlated time series, 13 with applications in dendroclimatology and hydrometeorology. Journal of Climate and Applied 14 Meteorology 23, 201-213.

15 Wigley, T.M.L., Jones, P.D., Briffa, K.R., 1987. Cross-dating Methods in Dendrochronology.

16 Journal of Archaeological Science 14, 51-64.

Wilmking, M., Juday, G.P., Barber, V.A., Zald, H.S.J., 2004. Recent climate warming forces contrasting growth responses of white spruce at treeline in Alaska through temperature thresholds. Global Change Biology 10, 1724-1736.

Wilson, R., D’Arrigo, R., Buckley, B., Büntgen, U., Esper, J., Frank, D., Luckman, B., Payette, S., Vose, R., Youngblut, D., 2007. A matter of divergence: Tracking recent warming at hemispheric scales using tree ring data. Journal of Geophysical Research 112,

23 doi:10.1029/2006JD008318.

Wilson, R., Luckman, B., 2003. Dendroclimatic reconstruction of maximum summer temperatures from upper tree-line sites in interior British Columbia. The Holocene 13, 853-863.

Yarie, J., Van Cleve, K., 2010. Long-term monitoring of climatic and nutritional affects on tree growth in interior Alaska. Canadian Journal of Forest Research 40, 1325-1335.

Youngblut, D., Luckman, B., 2008. Maximum June-July temperatures in the southwest Yukon over the last 300 years reconstructed from tree rings. Dendrochronologia 25, 153-166. 


\section{$1 \quad$ List of Tables}

3 Table 1. White spruce sites in the Mackenzie Delta region; 'Site no.' indicates the site's location 4 on Fig. 1.

6 Table 2. Correlations between monthly climate variables and tree-ring width indices: MDRC

7 (Fig. 3a); ' 1 st diff.' (mean of all $1^{\text {st }}$ differenced tree indices; Fig. 3e); and 'DFRC' (Divergence

8 Free Regional Chronology; Fig. 4f). Only correlations significant at $\mathrm{p} \leq 0.05$ (two-tailed) are

9 shown; correlations significant at $\mathrm{p} \leq 0.01$ (two-tailed) are in bold font.

11 Table 3. The frequency, percentage, and mean and median ages (years) of Group 1 and Group 2 12 trees at each site.

14 Table 4. Split-period calibration and verification, and full-period (AD 1893-2007) calibration 15 statistics for linear regression models of June-July minimum temperatures as a function of the 16 DFRC.

Table 5. Ranking of the ten warmest and ten coolest reconstructed decade-averaged minimum temperatures since $\mathrm{AD} 1245$. 


\section{List of Figures}

Figure 1. White spruce study sites (white dotted circles) in the Mackenzie Delta region; site numbers correspond to Table 1; water bodies are shaded grey; boreal treeline is delineated from the Circumpolar Arctic Vegetation Map (Walker et al., 2005). Inset box shows the locations of white spruce sites from other studies (grey dotted circles); site networks from the same study are bounded together.

Figure 2. Comparisons between each of the 29 site chronologies (black lines; calculated for all years defined $\geq 6$ trees) and regional mean chronologies (grey lines; the mean of all other trees from the remaining 28 sites). Upland sites are indicated (*); all other sites are delta plain sites. Inter-series correlations are in brackets; all correlations are significant at $\mathrm{p} \leq 0.001$.

Figure 3. (a) Mackenzie Delta Regional Chronology (dark grey line); 5-95 (light grey) and 2575 (medium grey) percentile ranges for all individual tree indices; MDRC sample depth (black line). (b) MDRC (grey) vs. reconstructed mean June-July temperatures - Szeicz and MacDonald (1995; black); markers (1) and (2) indicate the approximate points in time when early and late $20^{\text {th }}$ century divergence began, respectively. (c) MDRC (grey) vs. the mean of 6 hemisphericscale temperature reconstructions (black). (d) Mean chronology of the 5 upland sites (ESK, NL1, CDU, CDU1, \& CDU2; grey) vs. the Szeicz and MacDonald (1995) temperature reconstruction. (e) Mean of all first-differenced Mackenzie Delta tree indices (grey) vs. first-differenced JuneJuly instrumental mean temperatures (black). Note that the time axes differ between some plots. Refer to Supplementary Notes 3 and 4 for details on how the temperature reconstructions in plots (b)-(d) were calculated.

Figure 4. (a)-(c) Regional means for Group 1 (blue), Group 2 (red), and Snag (black) ring-width indices; regional means are shown for years with EPS $\geq 0.7$ (EPS $\geq 0.85$ noted); 5-95 (light grey) and 25-75 (medium grey) percentile ranges. (d) Comparison of the Group 1, Group 2 and, Snag regional chronologies. (e) Interannual standard deviations (grey) from all tree indices; a 41-year cubic smoothing spline (green) is used to highlight the low-frequency trend. (f) Divergence-Free Regional Chronology.

Figure 5. Comparisons of the Group 1 (grey) and Group 2 (black) regional averages based on 3 different detrending methods: (a) negative exponential/straight line; (b) horizontal mean; and (c) regional curve standardisation.

Figure 6. Mackenzie Delta regional June-July minimum temperature reconstruction (dark grey; $2 \times$ SE interval, light grey) versus: (a) instrumental (observed) June-July minimum temperatures; (b) Szeicz and MacDonald (1995) ring-width-based June-July mean temperature reconstruction;

(c) Porter et al. (2013) tree-ring $\delta^{18} \mathrm{O}$-based April-July temperature reconstruction; (d) Porter and Pisaric (2011) OCF-Group 2 ring-width chronology, June minimum temperature proxy; (e) D'Arrigo et al. (2009) Coppermine River ring-width chronology, June-July temperature proxy; 
1 circum-Arctic temperature reconstruction. Correlations represent the period of overlap between

2 the Mackenzie Delta reconstruction and the comparison series; all correlations are significant at $3 \mathrm{p} \leq 0.001$. Refer to Supplementary Note 5 for details on each comparison series, some of which 4 are modified from their original published form. Note that the time axes differ between some 5 plots. 
1 Table 1. White spruce sites in the Mackenzie Delta region; 'Site no.' indicates the site's location 2 on Fig. 1.

\begin{tabular}{|c|c|c|c|c|c|c|c|}
\hline $\begin{array}{l}\text { Site } \\
\text { no. }\end{array}$ & $\begin{array}{l}\text { Site } \\
\text { code }\end{array}$ & $\begin{array}{l}\text { Lat. } \\
\left({ }^{\circ} \mathrm{N}\right)\end{array}$ & $\begin{array}{l}\text { Long. } \\
\left({ }^{\circ} \mathrm{W}\right)\end{array}$ & $\begin{array}{l}\text { No. } \\
\text { trees }\end{array}$ & $\begin{array}{l}\text { First } \\
\text { year }\end{array}$ & $\begin{array}{l}\text { Last } \\
\text { year }\end{array}$ & $\begin{array}{l}\text { Mean series } \\
\text { length (yrs) }\end{array}$ \\
\hline 1 & ${ }^{\mathrm{a}} \mathrm{ESK}$ & 69.13 & 132.22 & 25 & 1172 & 1990 & 266 \\
\hline 2 & *NL1 & 68.59 & 133.68 & 49 & 1653 & 2006 & 202 \\
\hline 3 & ${ }^{\mathrm{b}} \mathrm{CDU}$ & 68.28 & 133.34 & 64 & 1060 & 1992 & 261 \\
\hline 4 & ${ }^{*} \mathrm{CDU} 1$ & 68.27 & 133.41 & 39 & 1158 & 2007 & 205 \\
\hline 5 & *CDU2 & 68.16 & 133.76 & 49 & 1118 & 2007 & 239 \\
\hline 6 & ${ }^{\mathrm{c}} \mathrm{TM}$ & 68.40 & 133.80 & 35 & 1529 & 2003 & 225 \\
\hline 7 & ${ }^{\circ} \mathrm{DW}$ & 68.43 & 133.81 & 39 & 1483 & 2003 & 306 \\
\hline 8 & ${ }^{c} \mathrm{BB}$ & 68.45 & 133.85 & 75 & 1501 & 2006 & 258 \\
\hline 9 & ${ }^{\mathrm{c}} \mathrm{MP}$ & 68.46 & 133.87 & 59 & 1545 & 2003 & 232 \\
\hline 10 & ${ }^{\mathrm{c}} \mathrm{M}$ & 68.47 & 133.85 & 29 & 1398 & 2003 & 234 \\
\hline 11 & ${ }^{\mathrm{c}} \mathrm{FT}$ & 68.52 & 133.86 & 44 & 1332 & 2003 & 244 \\
\hline 12 & ${ }^{\circ} \mathrm{MS}$ & 68.51 & 134.00 & 42 & 1611 & 2003 & 262 \\
\hline 13 & ${ }^{\circ} \mathrm{HL}$ & 68.58 & 134.10 & 27 & 1563 & 2003 & 340 \\
\hline 14 & $* \mathrm{AC} 1$ & 68.68 & 134.52 & 52 & 1579 & 2006 & 277 \\
\hline 15 & $* \mathrm{AM} 1$ & 68.61 & 134.38 & 39 & 1435 & 2007 & 254 \\
\hline 16 & $* \mathrm{NC} 2$ & 68.41 & 134.26 & 40 & 1687 & 2007 & 232 \\
\hline 17 & $* \mathrm{KC} 2$ & 68.27 & 134.16 & 42 & 1596 & 2007 & 259 \\
\hline 18 & $* \mathrm{KC} 1$ & 68.12 & 134.16 & 52 & 1445 & 2007 & 225 \\
\hline 19 & ${ }^{*} \mathrm{ES} 1$ & 68.14 & 134.77 & 51 & 1607 & 2007 & 272 \\
\hline 20 & *AK1 & 68.26 & 134.74 & 46 & 1631 & 2006 & 230 \\
\hline 21 & *AK2 & 68.28 & 134.79 & 13 & 1716 & 2006 & 235 \\
\hline 22 & ${ }^{*} \mathrm{SC} 1$ & 68.36 & 134.66 & 54 & 1603 & 2007 & 240 \\
\hline 23 & $* \mathrm{NC} 1$ & 68.43 & 134.58 & 46 & 1580 & 2007 & 229 \\
\hline 24 & *PC1 & 68.54 & 134.64 & 59 & 1499 & 2007 & 256 \\
\hline 25 & *JA2 & 68.52 & 135.07 & 45 & 1453 & 2007 & 241 \\
\hline 26 & *JA1 & 68.37 & 134.97 & 42 & 1587 & 2007 & 255 \\
\hline 27 & *PE1 & 68.15 & 135.16 & 37 & 1615 & 2007 & 257 \\
\hline 28 & $* \mathrm{WC} 2$ & 68.32 & 135.20 & 51 & 1474 & 2007 & 232 \\
\hline 29 & $* \mathrm{WC} 1$ & 68.45 & 135.52 & 41 & 1591 & 2006 & 260 \\
\hline
\end{tabular}

3 Further information on each site: ${ }^{\mathrm{a} B e ́ g i n}$ et al. (2000); ${ }^{\mathrm{b}}$ Szeicz and MacDonald (1996); ${ }^{\text {P Pisaric et }}$ 4 al. (2007); *this study. 
1 Table 2. Correlations between monthly climate variables and tree-ring width indices: MDRC

2 (Fig. 3a); ' $1{ }^{\text {st }}$ diff.' (mean of all $1^{\text {st }}$ differenced tree indices; Fig. 3e); and 'DFRC' (Divergence

3 Free Regional Chronology; Fig. 4f). Only correlations significant at $\mathrm{p} \leq 0.05$ (two-tailed) are

4 shown; correlations significant at $\mathrm{p} \leq 0.01$ (two-tailed) are in bold font.

\begin{tabular}{|c|c|c|c|c|c|c|c|c|c|c|c|c|c|}
\hline & & Sep & Oct & Nov & Dec & Jan & Feb & Mar & Apr & May & Jun & Jul & Aug \\
\hline Total & MDRC & & & & -0.24 & & & & & & & & \\
\hline \multirow[t]{2}{*}{ Precip. } & $1^{\text {st }}$ diff. & & & & & & -0.24 & & 0.30 & & & & \\
\hline & DFRC & 0.22 & & & & & & & & & & & \\
\hline Min. & MDRC & & & & & & & & & & & & \\
\hline \multirow[t]{2}{*}{ Temp. } & $1^{\text {st }}$ diff. & & & & & -0.20 & & & & & 0.48 & 0.35 & \\
\hline & DFRC & 0.30 & & & 0.32 & 0.24 & 0.29 & 0.22 & 0.25 & & 0.56 & 0.43 & 0.23 \\
\hline Mean & MDRC & & & & & & & & & & & & \\
\hline \multirow[t]{2}{*}{ Temp. } & $1^{\text {st diff. }}$ & & & & & -0.20 & & & & & 0.49 & 0.35 & \\
\hline & DFRC & & & & 0.22 & & 0.23 & & & & 0.51 & 0.23 & \\
\hline Max. & MDRC & & & & & & & & & & & & \\
\hline \multirow[t]{2}{*}{ Temp. } & $1^{\text {st }}$ diff. & & & & & & & & & & 0.43 & 0.33 & \\
\hline & DFRC & & & & & & & & & & 0.41 & & \\
\hline
\end{tabular}


1 Table 3. The frequency, percentage, and mean and median ages (years) of Group 1 and Group 2 2 trees at each site.

\begin{tabular}{|c|c|c|c|c|c|c|c|c|}
\hline \multirow[b]{2}{*}{ Site } & \multicolumn{4}{|c|}{ Group 1} & \multicolumn{4}{|c|}{ Group 2} \\
\hline & $\begin{array}{l}\text { freq. } \\
\text { trees }\end{array}$ & $\begin{array}{l}\% \text { of } \\
\text { trees }\end{array}$ & $\begin{array}{c}\text { Mean } \\
\text { age }\end{array}$ & $\begin{array}{c}\text { Median } \\
\text { age }\end{array}$ & $\begin{array}{l}\text { freq. } \\
\text { trees }\end{array}$ & $\begin{array}{l}\% \text { of } \\
\text { trees }\end{array}$ & $\begin{array}{c}\text { Mean } \\
\text { age }\end{array}$ & $\begin{array}{c}\text { Median } \\
\text { age }\end{array}$ \\
\hline ESK & 2 & 15.4 & 329 & 329 & 11 & 84.6 & 274 & 263 \\
\hline NL1 & 31 & 81.6 & 207 & 227 & 7 & 18.4 & 214 & 238 \\
\hline CDU & 24 & 85.7 & 272 & 238 & 4 & 14.3 & 290 & 265 \\
\hline CDU1 & 13 & 46.4 & 184 & 189 & 15 & 53.6 & 209 & 192 \\
\hline CDU2 & 24 & 80.0 & 231 & 225 & 6 & 20.0 & 278 & 267 \\
\hline TM & 28 & 80.0 & 225 & 222 & 7 & 20.0 & 223 & 222 \\
\hline DW & 23 & 95.8 & 333 & 359 & 1 & 4.2 & 406 & 406 \\
\hline BB & 48 & 87.3 & 288 & 281 & 7 & 12.7 & 213 & 214 \\
\hline MP & 19 & 95.0 & 276 & 255 & 1 & 5.0 & 340 & 340 \\
\hline M & 15 & 93.8 & 263 & 241 & 1 & 6.3 & 183 & 183 \\
\hline FT & 18 & 100.0 & 261 & 270 & 0 & 0.0 & $\mathrm{n} / \mathrm{a}$ & $\mathrm{n} / \mathrm{a}$ \\
\hline MS & 30 & 78.9 & 254 & 242 & 8 & 21.1 & 282 & 259 \\
\hline HL & 18 & 66.7 & 336 & 358 & 9 & 33.3 & 348 & 367 \\
\hline $\mathrm{AC} 1$ & 30 & 81.1 & 307 & 327 & 7 & 18.9 & 308 & 288 \\
\hline AM1 & 27 & 96.4 & 266 & 253 & 1 & 3.6 & 258 & 258 \\
\hline $\mathrm{NC} 2$ & 17 & 68.0 & 254 & 258 & 8 & 32.0 & 259 & 258 \\
\hline $\mathrm{KC} 2$ & 23 & 85.2 & 282 & 258 & 4 & 14.8 & 247 & 254 \\
\hline $\mathrm{KC} 1$ & 24 & 66.7 & 234 & 224 & 12 & 33.3 & 242 & 254 \\
\hline ES1 & 39 & 92.9 & 273 & 298 & 3 & 7.1 & 328 & 332 \\
\hline AK1 & 37 & 100.0 & 249 & 245 & 0 & 0.0 & $\mathrm{n} / \mathrm{a}$ & $\mathrm{n} / \mathrm{a}$ \\
\hline AK2 & 12 & 100.0 & 241 & 235 & 0 & 0.0 & $\mathrm{n} / \mathrm{a}$ & $\mathrm{n} / \mathrm{a}$ \\
\hline $\mathrm{SC} 1$ & 38 & 90.5 & 251 & 242 & 4 & 9.5 & 222 & 214 \\
\hline $\mathrm{NC} 1$ & 24 & 92.3 & 261 & 250 & 2 & 7.7 & 284 & 284 \\
\hline $\mathrm{PC} 1$ & 48 & 98.0 & 258 & 245 & 1 & 2.0 & 211 & 211 \\
\hline JA2 & 30 & 85.7 & 243 & 251 & 5 & 14.3 & 258 & 255 \\
\hline JA1 & 23 & 92.0 & 276 & 266 & 2 & 8.0 & 289 & 289 \\
\hline PE1 & 23 & 95.8 & 289 & 303 & 1 & 4.2 & 233 & 233 \\
\hline WC2 & 37 & 94.9 & 233 & 234 & 2 & 5.1 & 318 & 318 \\
\hline WC1 & 24 & 77.4 & 259 & 266 & 7 & 22.6 & 304 & 297 \\
\hline $\begin{array}{c}\text { Average } \\
\text { site* }\end{array}$ & 25.8 & 81.7 & 263.2 & 261.6 & 5.2 & 18.3 & 269.9 & 267.6 \\
\hline
\end{tabular}

$3 *$ Based on sites that have both response types (i.e., all sites except FT, AK1, and AK2). 
1 Table 4. Split-period calibration and verification, and full-period (AD 1893-2007) calibration 2 statistics for linear regression models of June-July minimum temperatures as a function of the 3 DFRC.

\begin{tabular}{lccc}
\hline & Split 1 & Split 2 & Full period \\
\hline Calibration & & & \\
Period & $1893-1954$ & $1955-2007$ & $1893-2007$ \\
$\mathrm{~N}$ & 53 & 53 & 106 \\
Slope & 3.27 & 1.69 & 2.07 \\
Intercept & 2.17 & 4.06 & 3.46 \\
$\mathrm{r}$ & 0.44 & 0.49 & 0.60 \\
$\mathrm{r}^{2}$ & 0.20 & 0.24 & 0.36 \\
Adjusted $\mathrm{r}^{2}$ & 0.18 & 0.23 & 0.35 \\
SE & 0.81 & 0.88 & 0.86 \\
DW & 1.78 & 1.84 & 1.86 \\
Sign (+/-) & $34 / 18^{*}$ & $32 / 21$ & $65 / 40^{*}$ \\
\hline Verification & & & \\
Period & $1955-2007$ & $1893-1954$ & $\mathrm{n} / \mathrm{a}$ \\
$\mathrm{N}$ & 53 & 53 & $\mathrm{n} / \mathrm{a}$ \\
$\mathrm{r}$ & 0.49 & 0.44 & $\mathrm{n} / \mathrm{a}$ \\
$\mathrm{RE}$ & 0.39 & 0.57 & $\mathrm{n} / \mathrm{a}$ \\
$\mathrm{CE}$ & -0.15 & 0.08 & $\mathrm{n} / \mathrm{a}$ \\
\hline
\end{tabular}

4 N.B., Temperature data for June (1895 and 1896) and July (1893, 1900, and 1908) were not 5 available. To allow the calculation of June-July averages for these years, the missing data points 6 were estimated by the mean of the four closest years of data. The calibration/verification period 7 1893-1954 (62 years) contains only 53 years of valid data points, and 9 years of missing data. All 8 correlations are significant at $\mathrm{p} \leq 0.001$ (one-tailed); sign-test result significant at ${ }^{*} \mathrm{p} \leq 0.05$. 
1 Table 5. Ranking of the ten warmest and ten coolest reconstructed decade-averaged minimum 2 temperatures since AD 1245.

\begin{tabular}{cc|cc}
\hline Warm Decades & ${ }^{\circ} \mathrm{C}$ & Cool decades & ${ }^{\circ} \mathrm{C}$ \\
\hline $2000-2009$ & $* 7.4$ & $1810-1819$ & 4.9 \\
$1990-1999$ & 6.9 & $1280-1289$ & 4.9 \\
$1980-1989$ & 6.4 & $1820-1829$ & 5.0 \\
$1970-1979$ & 6.2 & $1270-1279$ & 5.0 \\
$1960-1969$ & 6.0 & $1830-1839$ & 5.0 \\
$1520-1529$ & 6.0 & $1290-1299$ & 5.0 \\
$1540-1549$ & 6.0 & $1840-1849$ & 5.0 \\
$1950-1959$ & 6.0 & $1260-1269$ & 5.1 \\
$1770-1779$ & 5.9 & $1700-1709$ & 5.1 \\
$1530-1539$ & 5.9 & $1340-1349$ & 5.1 \\
\hline
\end{tabular}

3 *Based on AD 2000-2007 reconstructed and AD 2008-2009 observed temperatures. 


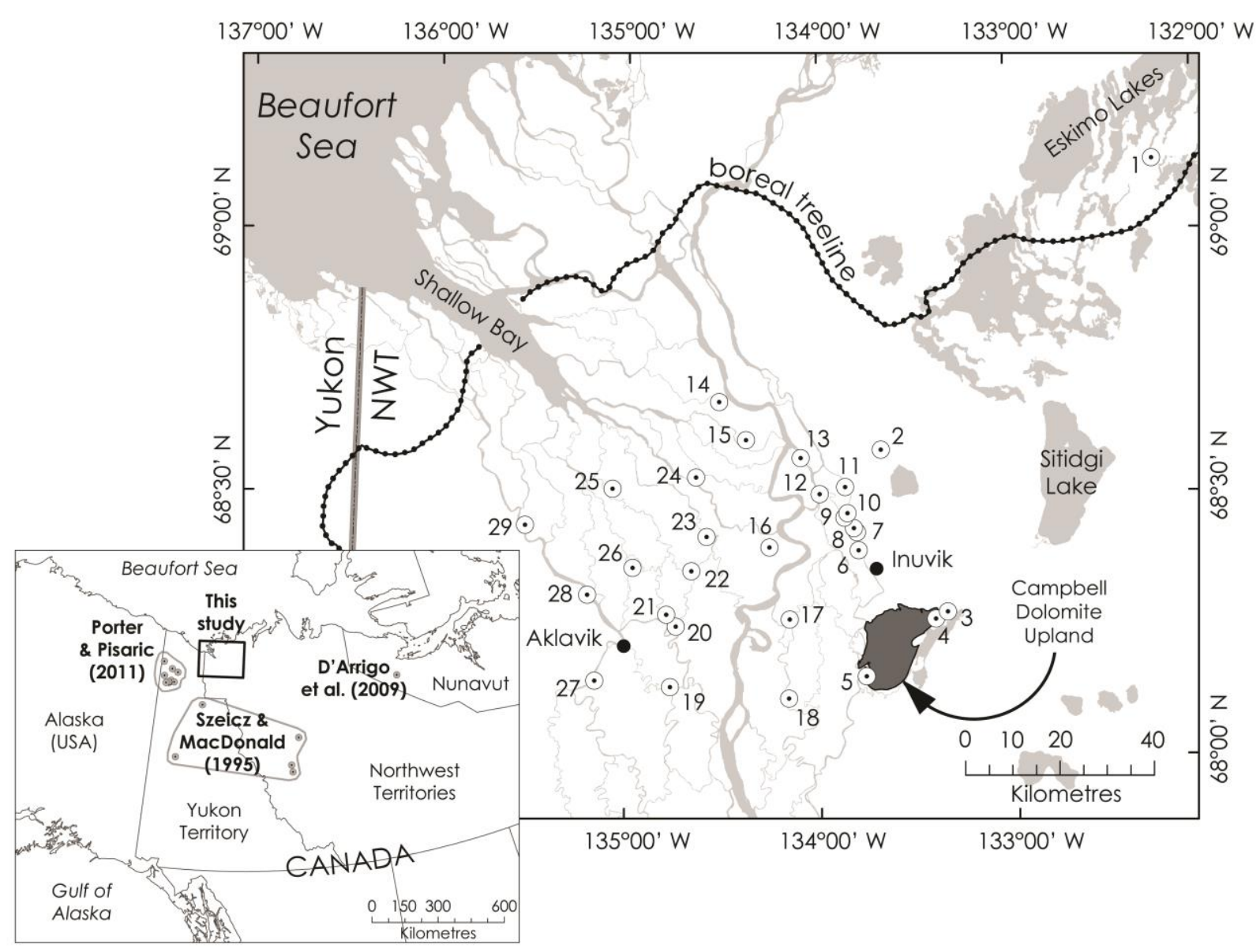

2 Figure 1.

3

4 
Year AD
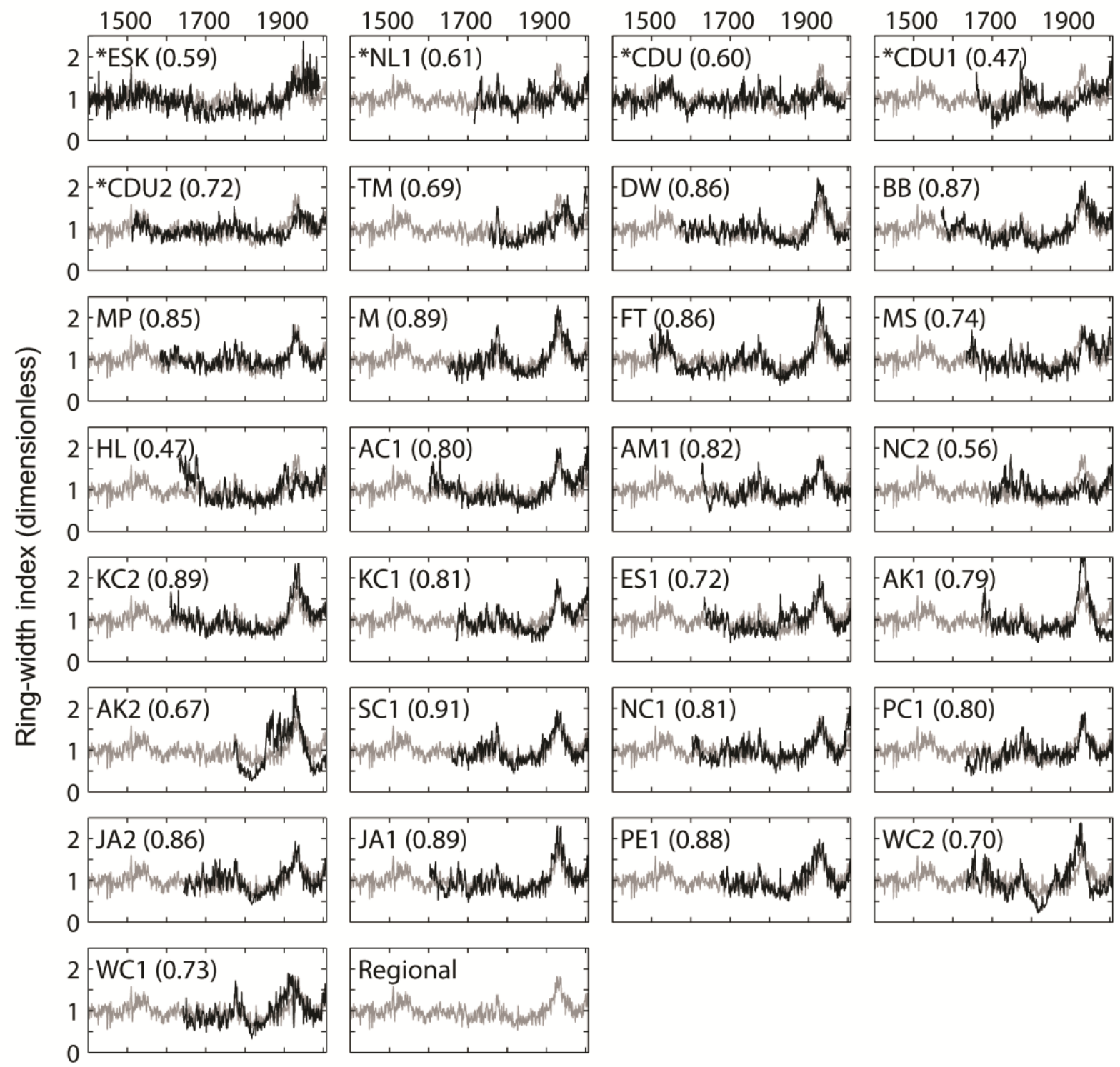

Figure 2. 

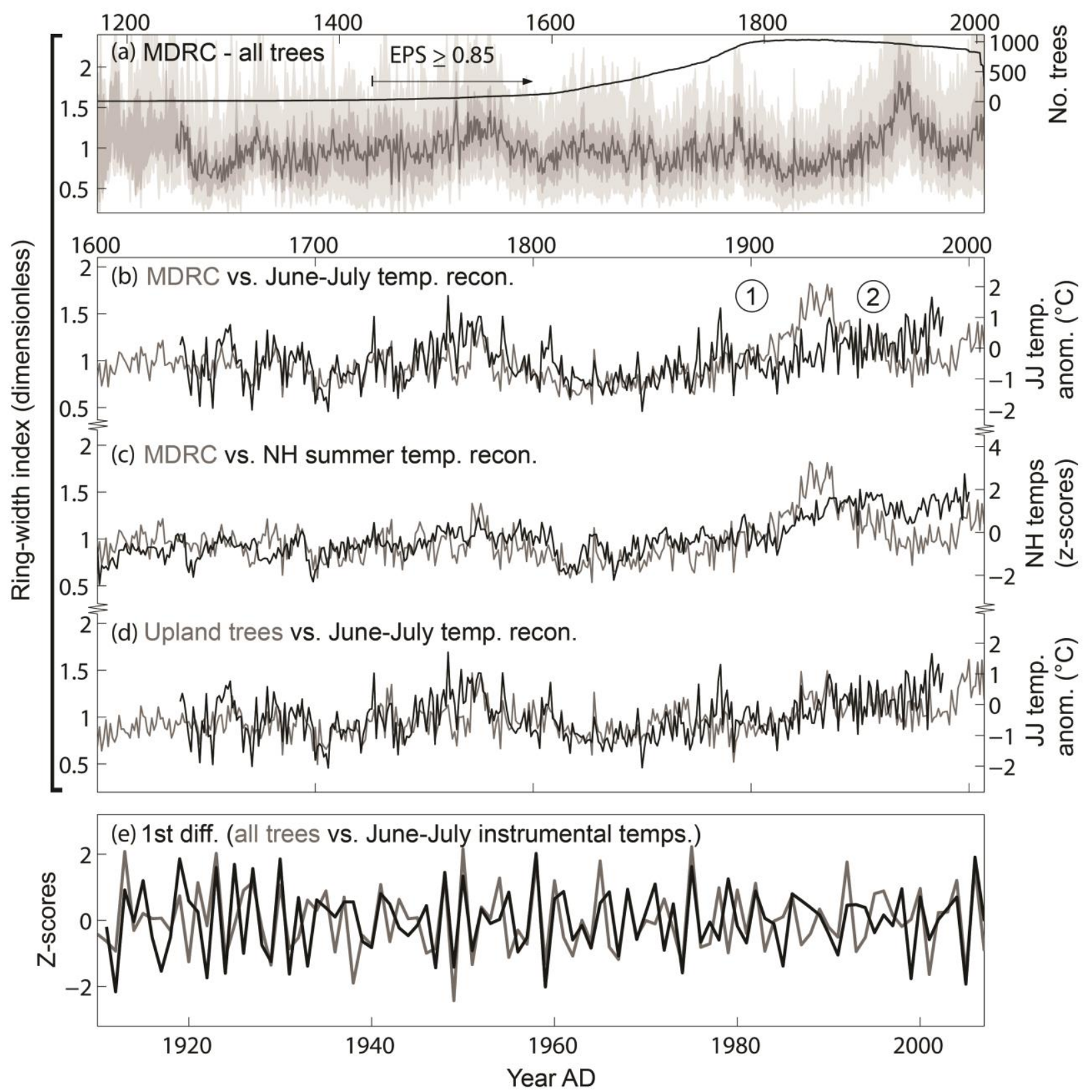

2

3

4

5

6

7

8

9

10

Figure 3. 


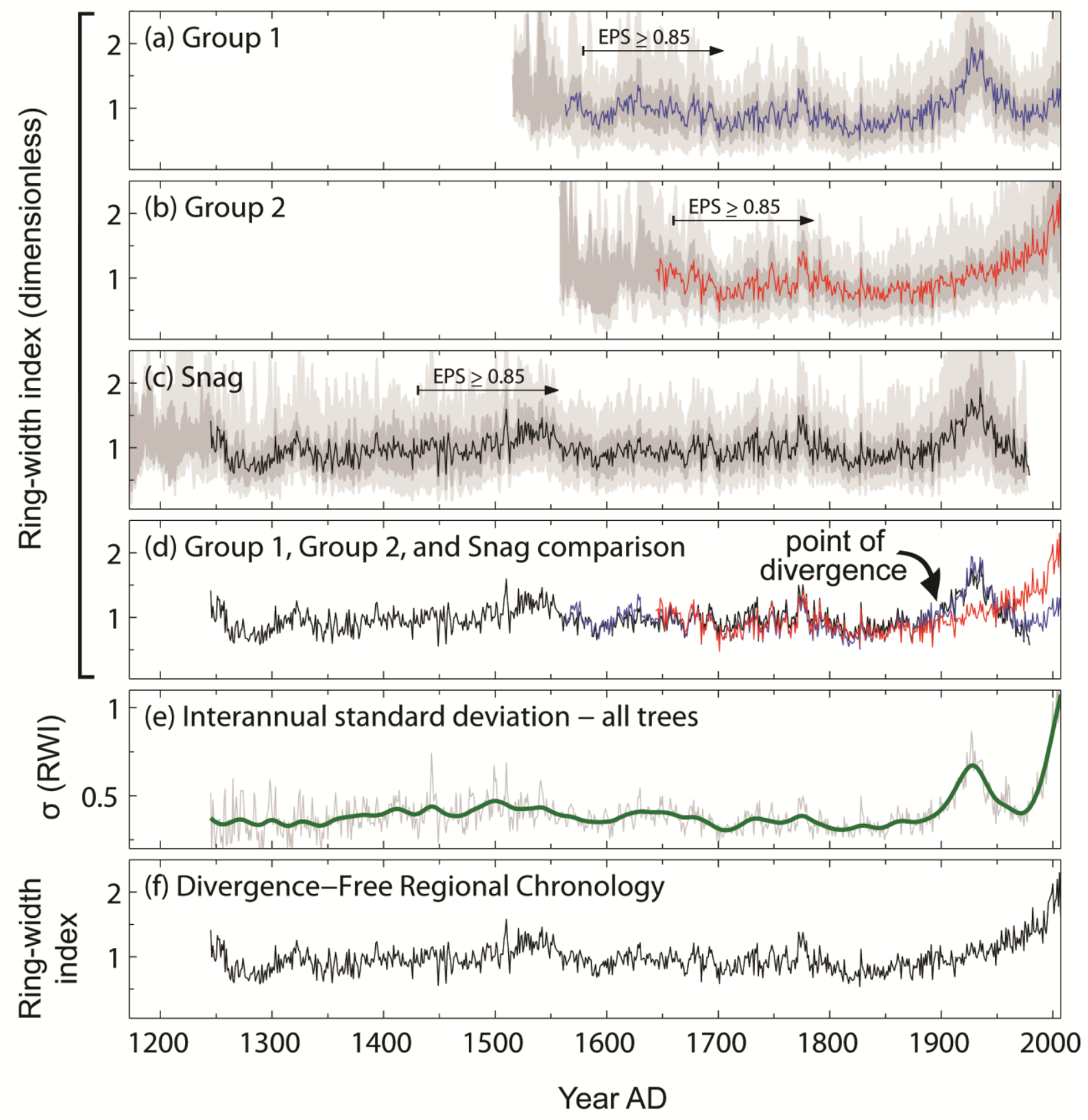




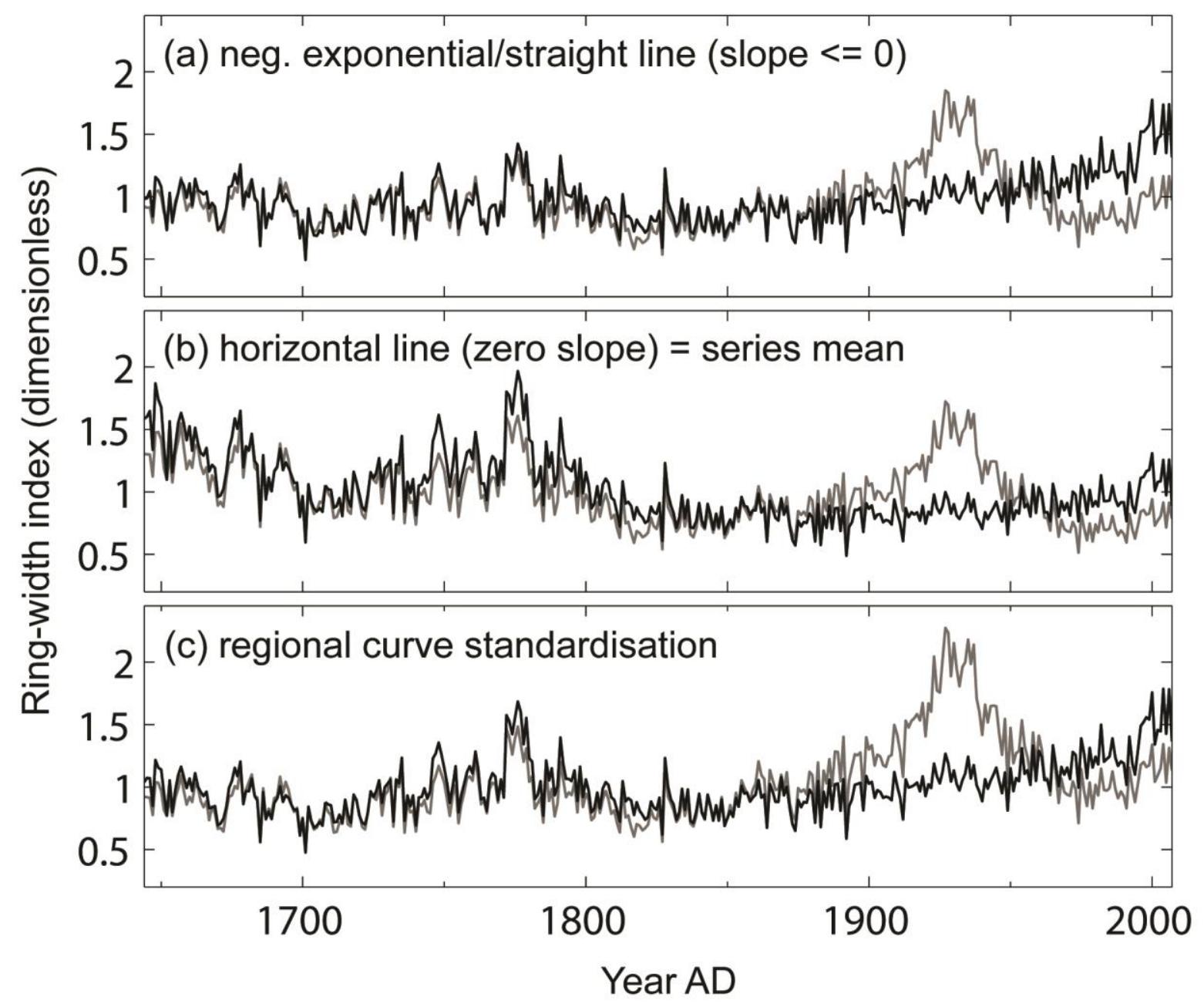

Figure 5. 

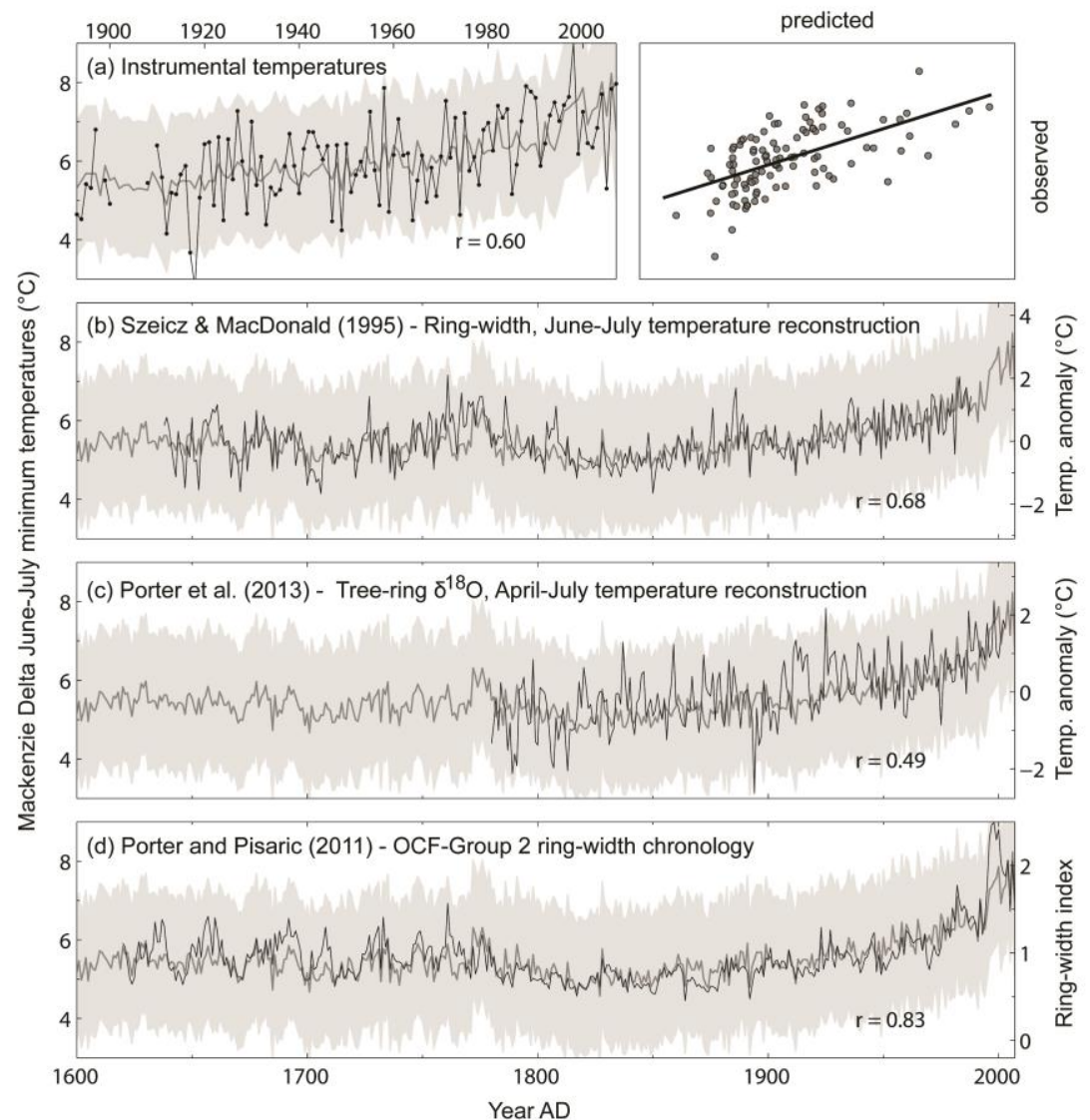
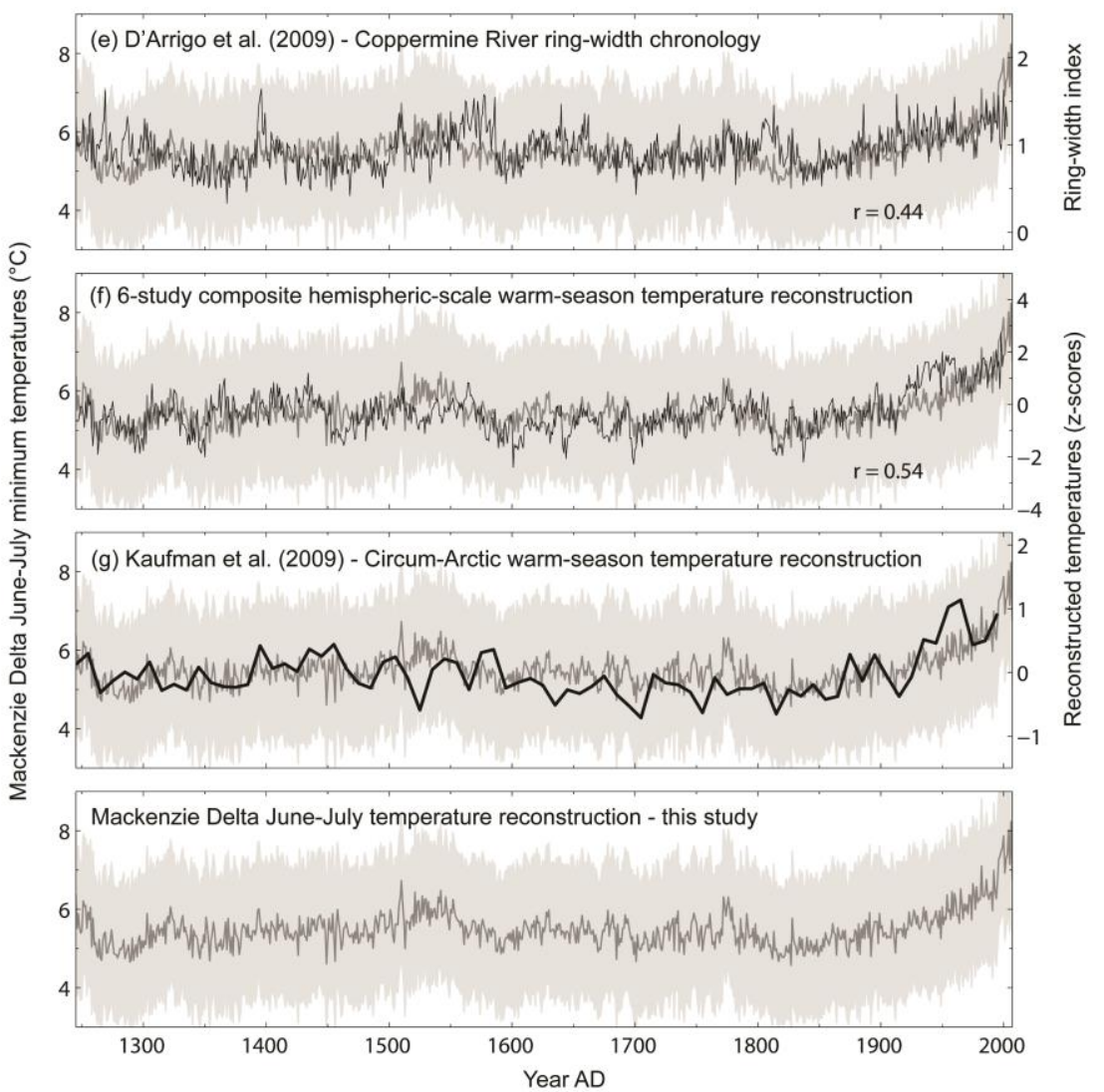

1

\section{Figure 6.}


Supplementary Notes and Figures

2

3

4

5

6

7

8

9

10

11

12

13

14

15

16

17

18

19

20

21

22

23

24

25

26

27

28

29

30

31

32

33

34

35

36 


\section{Supplementary Note 1.}

2 Raw data for the eastern delta sites were provided by M. Pisaric. The ESK data were

3 provided by C. Bégin (Geological Survey of Canada). The CDU data (independent from 'CDU1'

4 and 'CDU2') were obtained from two sources: the original Szeicz and MacDonald (1996) dataset

5 was obtained from the International Tree-Ring Databank (file CANA138); an additional 11 trees

6 sampled by Szeicz and MacDonald, but not published until Esper et al. (2002; see also Frank et

7 al., 2007), were also included. These additional CDU series were provided by D. Frank (Swiss

8 Federal Research Institute, WSL).

9 The program COFECHA (Holmes, 1983) was used to validate the cross-dating quality of

10 the above mentioned data. Nine of the 49 ESK series contained continuous sections (decades to

11 centuries) of 'B-type' errors at the ends of the series indicating that they were potentially

12 misaligned with respect to the master series. The remaining portions of these series were not in

13 question as they were strongly correlated with the master series. As the physical samples were

14 not at our disposal, we could not re-measure the problem sections and assess the cause of these

15 errors (e.g., reaction growth, locally absent rings, etc.). To ensure these potential errors would

16 not bias the mean ESK chronology, the problem sections were excluded from further analysis.

18 Supplementary Note 2.

19 For the regional temperature composites (Supplementary Figs. 5-7), monthly temperature

20 records for Tuktoyaktuk, Inuvik, Aklavik, Fort McPherson, Norman Wells, and Fort Good Hope

21 were downloaded from Environment Canada (http://climate.weatheroffice.gc.ca/). The Fort

22 McPherson record consists of data from the original 'Fort McPherson' station (AD 1892-1977)

23 and the newer 'Fort McPherson A' station (AD 1981-2007) ca. $3 \mathrm{~km}$ from the original station (É. 
1 Mekis, Environment Canada, pers. comm.); only the AD 1892-1977 data are used due to a high

2 number of estimated, missing, or incomplete data points in the new station record. Furthermore,

3 there is no overlap between the new and old stations, making it impossible to identify and adjust

4 for systematic biases due to geographical position. The Fort Good Hope record is a composite of

5 data from the original 'Fort Good Hope 2' station (AD 1897-1966; temperature data available

6 since AD 1908) and the 'Fort Good Hope A' station (AD 1944-2007) ca. $1 \mathrm{~km}$ from the original

7 station. The mean and variance of the Fort Good Hope 2 record were adjusted to the Fort Good

8 Hope A record to account for systematic differences due to location, and combined into a mean

9 record. The Mackenzie Delta regional temperature composites (Supplementary Figs. 5-7) were

10 developed by first adjusting the mean and variance of each station record to that of the Inuvik

11 record, and then averaging all records to create regional monthly composites.

12 The regional precipitation composites (Supplementary Fig. 8) were developed from

13 Inuvik, Aklavik, and Fort McPherson data only. The reason only these stations were used is

14 because precipitation is highly variable over short distances in the study region (Burn and

15 Kokelj, 2009), and including stations that are more distant from the site network would diminish

16 the representativeness of the regional composites with respect to our sample trees. Inuvik,

17 Aklavik, and Fort McPherson are the most proximal stations to and are likely most representative

18 of the site network. Precipitation data for Inuvik (1957-2007) and Fort McPherson (1932-2007)

19 were downloaded from the Adjusted and Homogenised Canadian Climate Database

20 (http://ec.gc.ca/dccha-ahccd), which are adjusted for gauge changes and trace snow and rainfall

21 events (Mekis and Vincent, 2011). Trace events ( $<0.2 \mathrm{~mm}$ rain, $<0.2 \mathrm{~cm}$ snow) cannot be

22 accurately measured, and are assigned a value of zero and flagged in raw climate records. In

23 Arctic regions, trace events can account for a major proportion of the total monthly precipitation 
1 budget, and trace-adjusted data are an attempt to better reflect actual precipitation amounts. Only

2 raw monthly data were available for Aklavik (AD 1926-2007;

3 http://climate.weatheroffice.gc.ca/). However, over the 81 year period of station operation, 432

4 monthly observations were reported and just 10 of the observations were flagged as trace events.

5 These 10 trace events were excluded from the Aklavik record to make it more comparable to the

6 Inuvik and Fort McPherson records. The Aklavik record was as well correlated with the adjusted

7 Inuvik record as the 2 adjusted records were with each other $(r=0.43$ and 0.36 , respectively, for

8 the average month; $\mathrm{p} \leq 0.05$ ) suggesting that all 3 records exhibit a similar level of intra-regional

9 coherence. The Mackenzie Delta regional precipitation composites (Supplementary Fig. 8) were

10 developed by first adjusting the mean and variance of the Aklavik and Fort McPherson records

11 to that of the Inuvik record, and averaging the three records to create regional monthly

12 composites.

\section{Supplementary Note 3.}

15 The Szeicz and MacDonald (1995) June-July temperature reconstruction (AD 1638-

16 1988) was obtained from NOAA's Paleoclimatology Program archive (http://www.ncdc.noaa.

17 gov/paleo/recons.html) and converted to anomalies with respect to its mean value over the period $18 \quad$ AD 1638-1988.

\section{$20 \quad$ Supplementary Note 4.}

21 The 6-study hemispheric-scale composite temperature reconstruction consists of the

22 following reconstructions: Jones et al. (1998); Briffa (2000); Esper et al. (2002); D'Arrigo et al.

23 (2006); Wahl and Ammann (2007); Wilson et al. (2007). The reconstructions were obtained from 
1 NOAA's Paleoclimatology Program archive (http://www.ncdc.noaa.gov/paleo/recons.html). The

2 reconstructions are largely tree-ring based, and overall the composite reconstruction is weighted

3 towards samples from the Northern Hemisphere. Z-scores were calculated for each

4 reconstruction based on their common period of overlap (AD 1750-1980) and averaged into the

5 composite index using a robust bi-weight mean. We note that the Szeicz and MacDonald (1996)

6 'CDU' chronology used in our regional chronology was used by Esper et al. (2002); however,

7 the overall contribution of CDU to the Esper et al.(2002) reconstruction is small, and negligible

8 to the hemispheric-scale composite. As such, our regional chronology and the hemispheric-

9 composite can be considered almost entirely independent of each another.

\section{Supplementary Note 5.}

12 Details on comparison series illustrated in Fig. 5:

13 (a) See Supplementary Note 2;

14 (b) Ring-width-based June-July mean temperature reconstruction by Szeicz and MacDonald

15 (1995) (see Supplementary Note 3);

16 (c) Tree-ring $\delta^{18} \mathrm{O}$-based April-July minimum temperature reconstruction by Porter et al. (2013;

17 see also Porter et al., 2009). The reconstruction is expressed as anomalies from the long-term

18 mean (AD 1780-2003). The reconstruction was developed from a composite $\delta^{18} \mathrm{O}$ record from 6

19 white spruce trees from 'TM' site (site 6, Fig. 1), Mackenzie Delta;

20 (d) Unaltered OCF-Group 2 ring-width chronology by Porter and Pisaric (2011); regional mean

21 of 11 site-chronologies in Old Crow Flats, northern Yukon Territory, Canada;

22 (e) A signal-free version of the Coppermine River ring-width chronology by D'Arrigo et al. (2009),

23 West Nunavut, Canada. The signal-free chronology was calculated by Porter and Pisaric (2011); 
1 (f) 6-study composite hemispheric-scale temperature reconstruction (see Supplementary Note 4);

2 (g) Circum-Arctic, multi-proxy temperature reconstruction by Kaufman et al. (2009). The

3 original Kaufman et al. (2009) reconstruction uses 23 proxy records, 4 that are tree-ring-based.

4 We used the 19 non-tree-ring series only to calculate the circum-Arctic reconstruction shown in

5 Fig. 5g. The full Kaufman et al. (2009) dataset was obtained from the NOAA Paleoclimatology

6 Program archive (http://www.ncdc.noaa.gov/paleo/recons.html). Z-scores for the 19 series were

7 calculated based on their common period of overlap (AD 995-1795) and averaged into a

8 composite index using the robust bi-weight mean (Cook, 1985).

9

10

11

12

13

14

15

16

17

18

19

20

21

22

23 


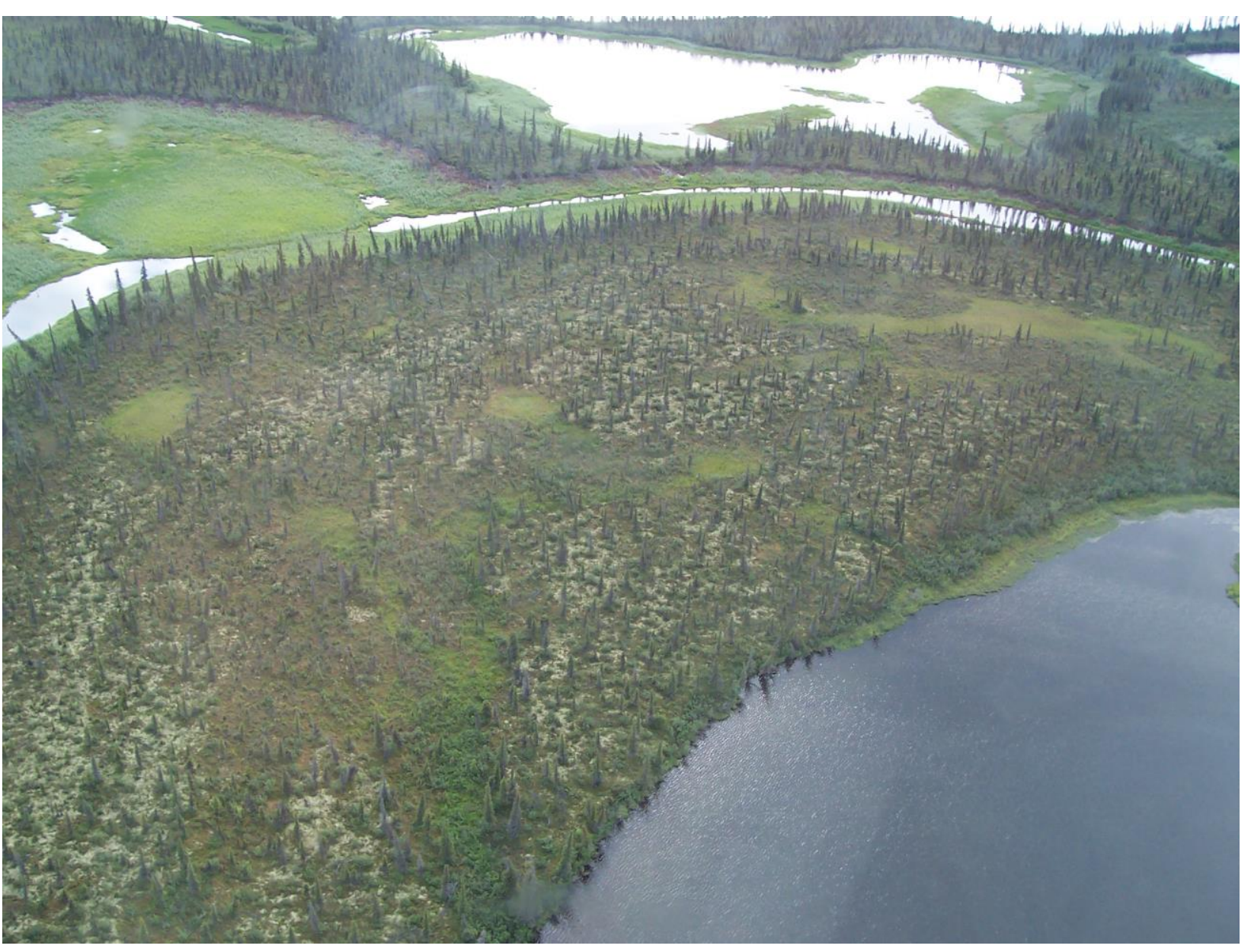

2 Supplementary Figure 1. An overhead view of a 'white spruce/crowberry-lichen' forest site 3 (Pearce et al., 1988) which is representative of most of the delta plain sites sampled in this study. 4 These sites are easy to spot from overhead due to their sparse canopies and abundance of 5 reflective lichen. 


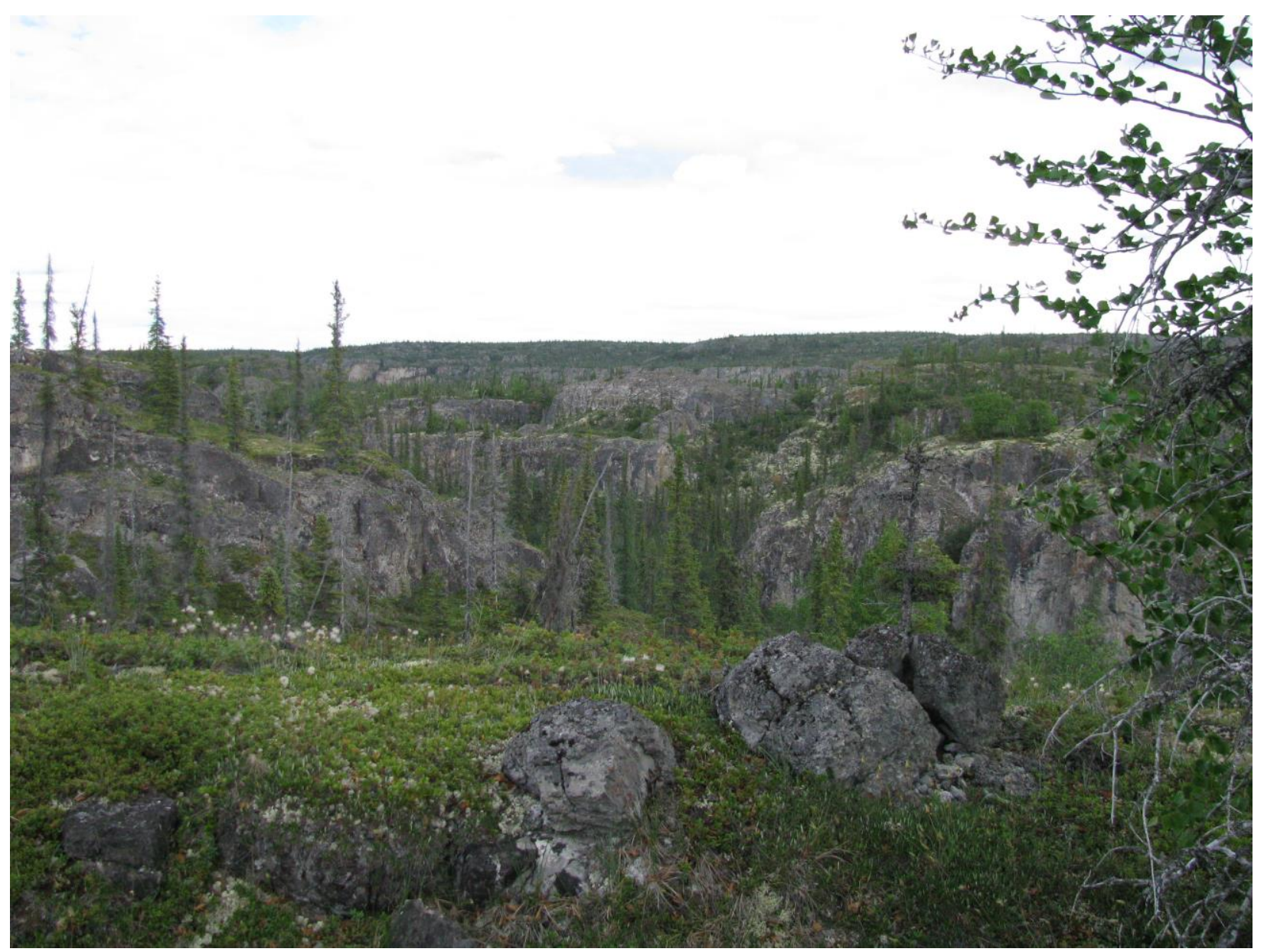

2 Supplementary Figure 2. A representative view of 'CDU2'. This site is characterised by an 3 open-canopy, thick understory of mosses and lichens, and an irregular, rocky terrain. These site 4 characteristics are also shared by 'CDU' and 'CDU1' (see also Fig. 2 of Szeicz and MacDonald, 5 1996). 


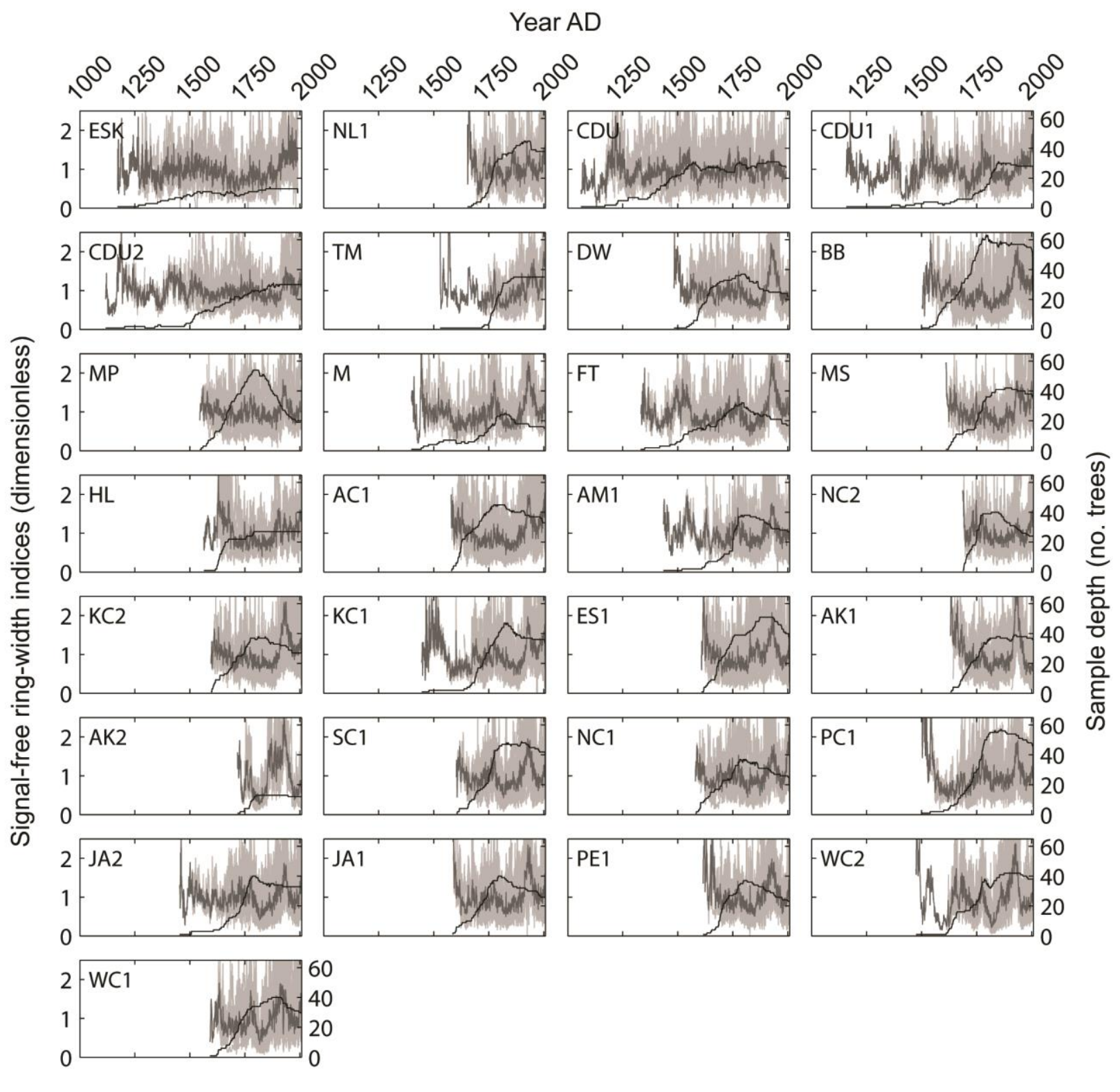

2 Supplementary Figure 3. Tree-averaged ring-width indices (light grey) and mean site 3 chronologies (dark grey) for all 29 sites; the number of trees defining each year of the mean site 4 chronologies is indicated (black).

5

6 


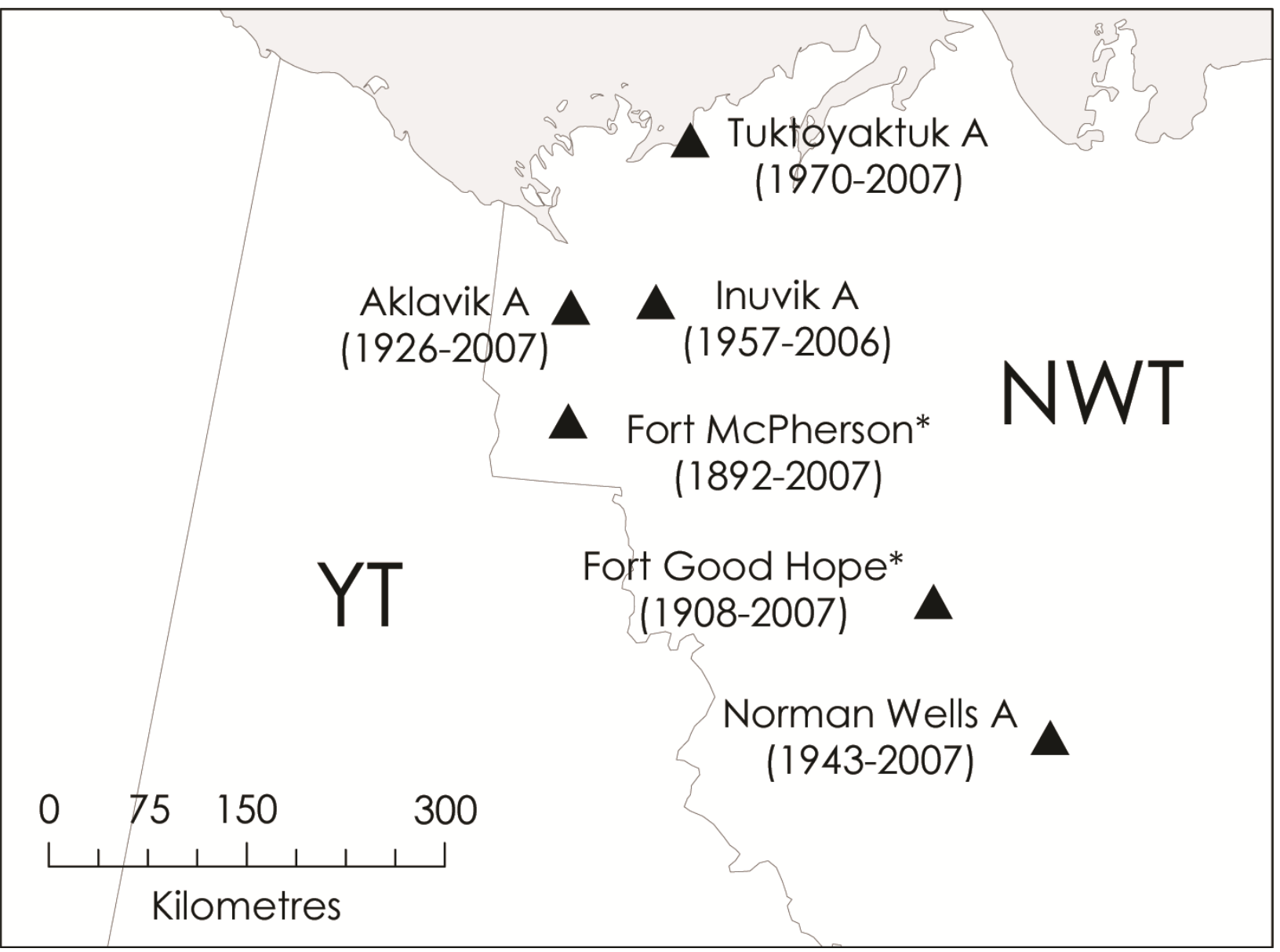

2 Supplementary Figure 4. Climate stations included in the regional temperature and 3 precipitation composites. Periods of station operation are indicated (n.b., data are not available 4 for all years of operation). 'Fort McPherson*' represents two non-overlapping station records: 5 'Fort McPherson' (1892-1977) and 'Fort McPherson A' (1981-2007). 'Fort Good Hope*' is a 6 merged record representing 'Fort Good Hope 2' (1897-1966) and 'Fort Good Hope A' (19447 2007). 

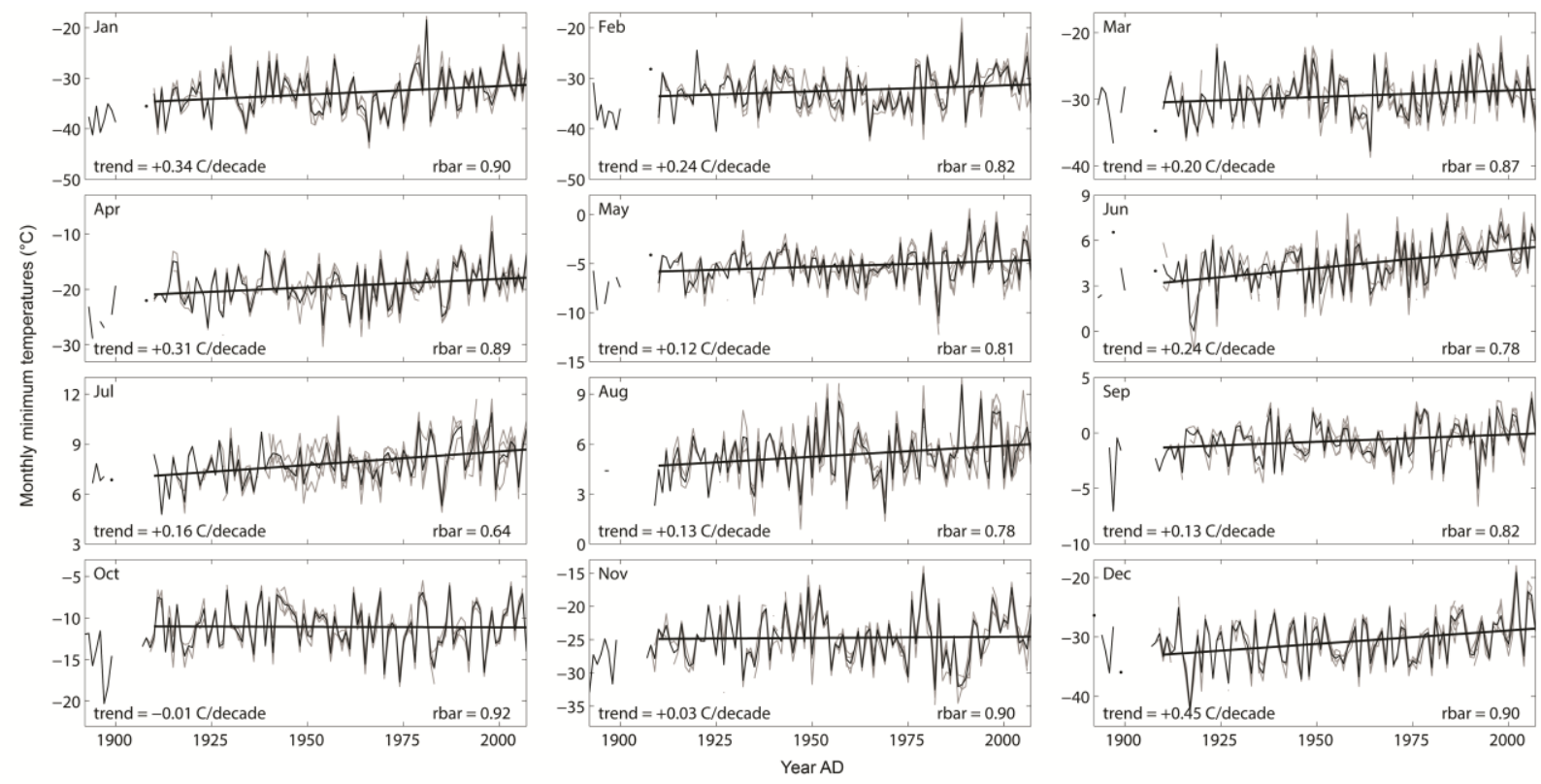

2 Supplementary Figure 5. Comparison of monthly minimum temperatures from Tuktoyaktuk, Inuvik, Aklavik, Fort McPherson, Norman Wells, and Fort Good Hope (grey lines); regional means (black lines). 'rbar' is the mean inter-series correlation (all are significant at $\mathrm{p} \leq 0.001$ ). 'trend' is the slope of the regional mean from AD 1910-2007, a period defined by two or more stations in most cases. See Supplementary Note 2 for more details. 

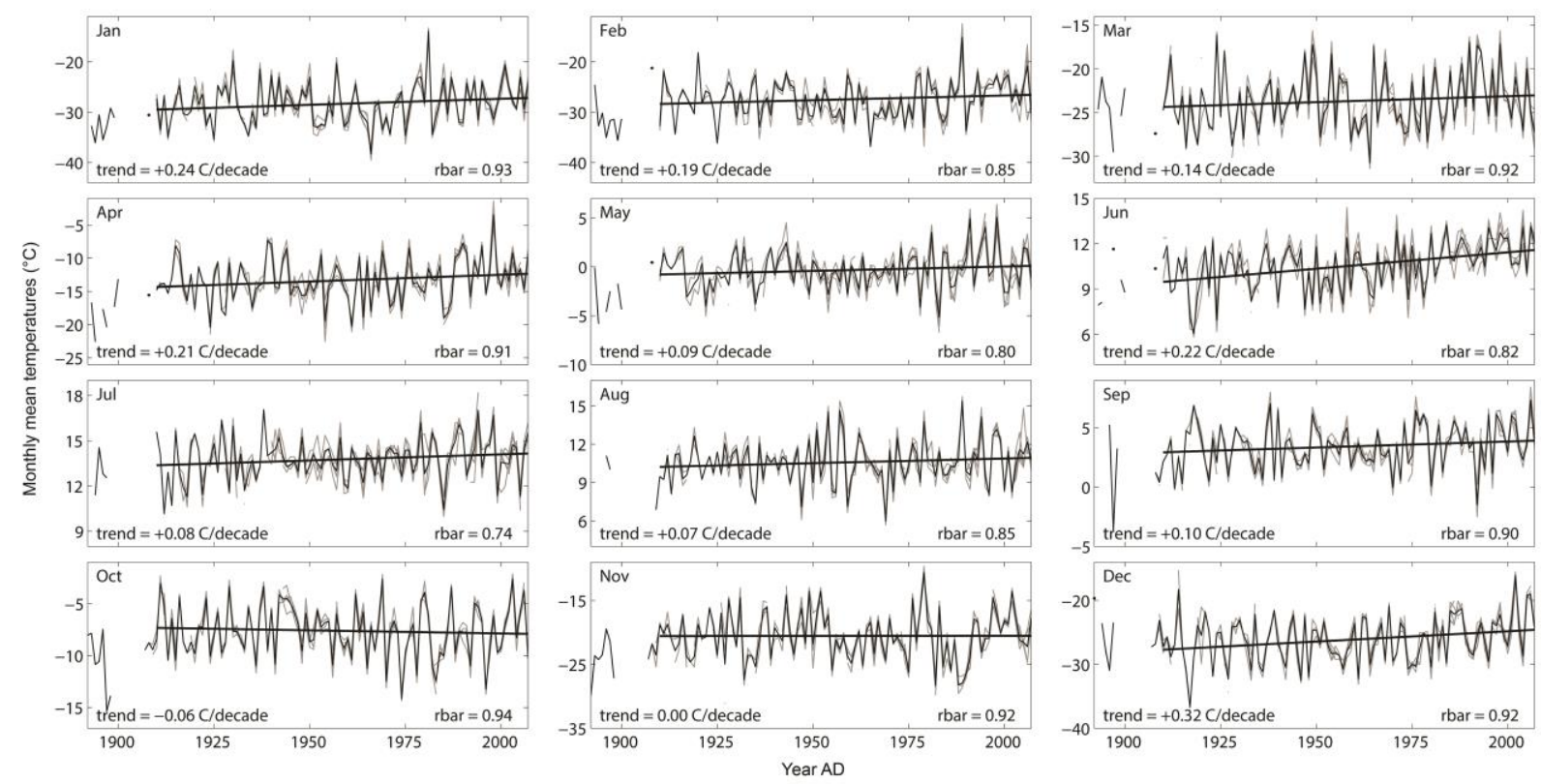

2 Supplementary Figure 6. Same as Supplementary Fig. 5 but for monthly mean temperatures. 

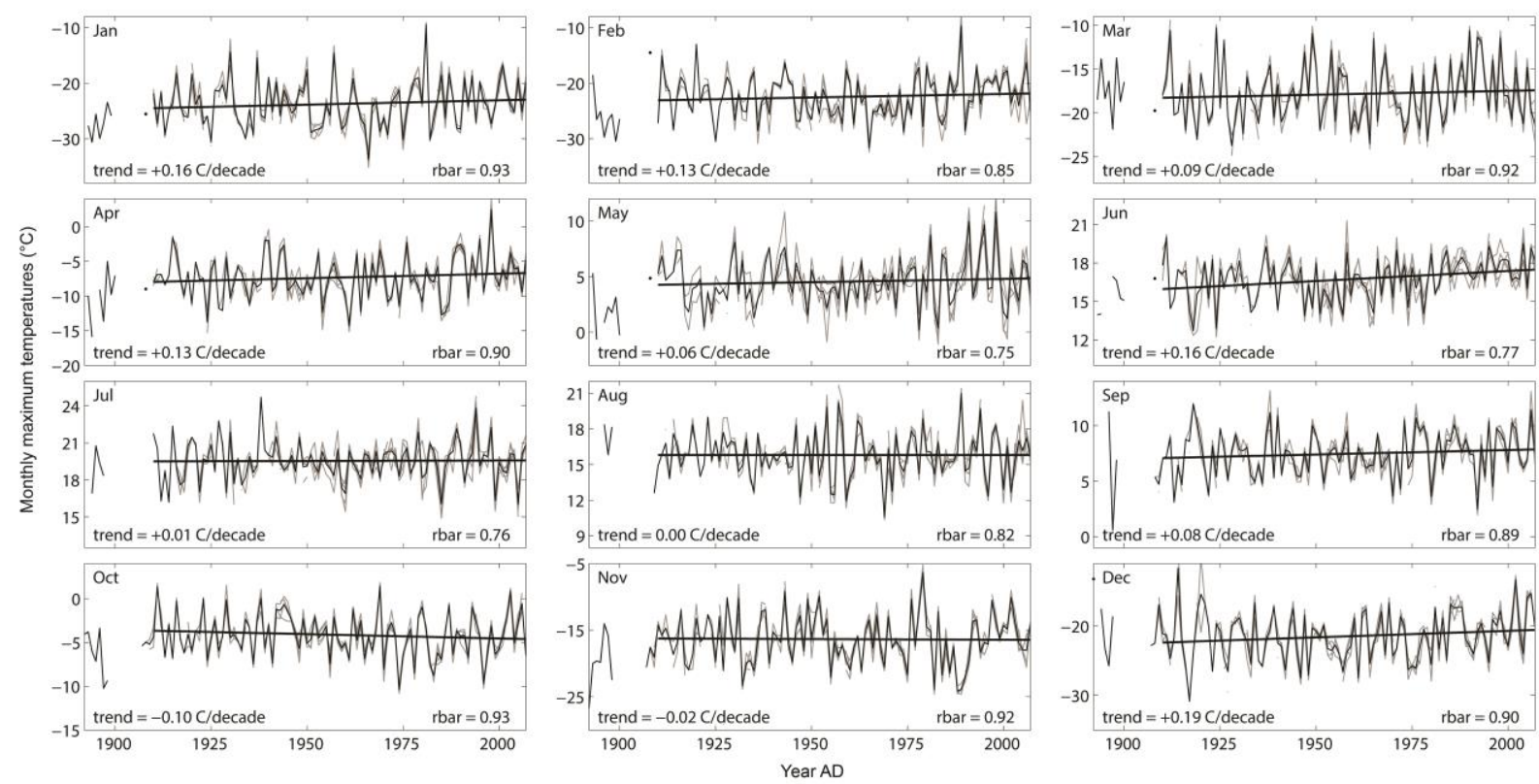

Supplementary Figure 7. Same as Supplementary Fig. 5 but for monthly maximum 3 temperatures. 

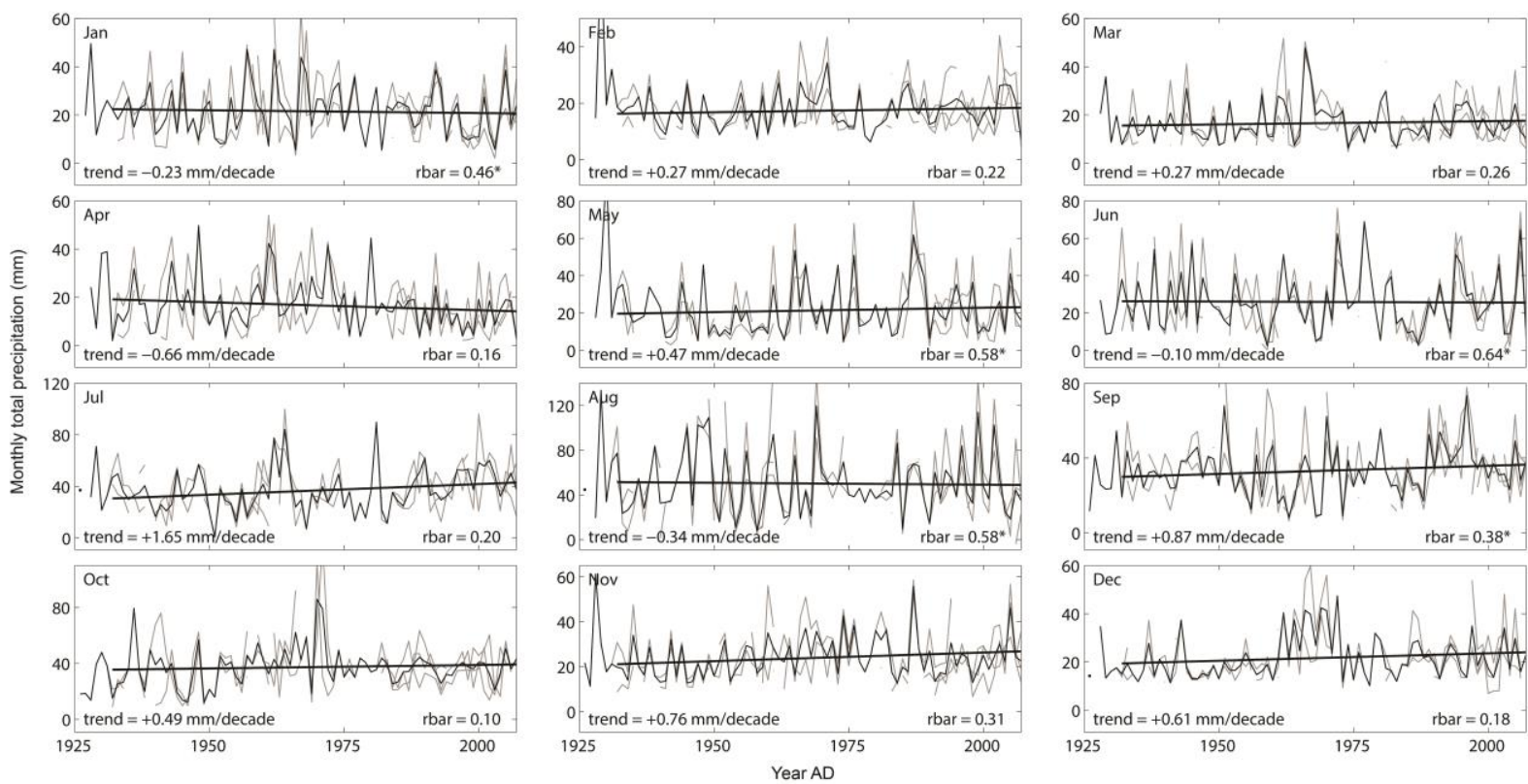

2 Supplementary Figure 8. Comparison of total monthly precipitation from Inuvik, Aklavik, and

3 Fort McPherson (grey lines); regional means (black line). 'rbar' is the mean inter-series 4 correlation $(* \mathrm{p} \leq 0.05)$. 'trend' is the slope of the regional mean from AD 1932-2007, a period defined by two or more stations in most cases. See Supplementary Note 2 for more details.

6 


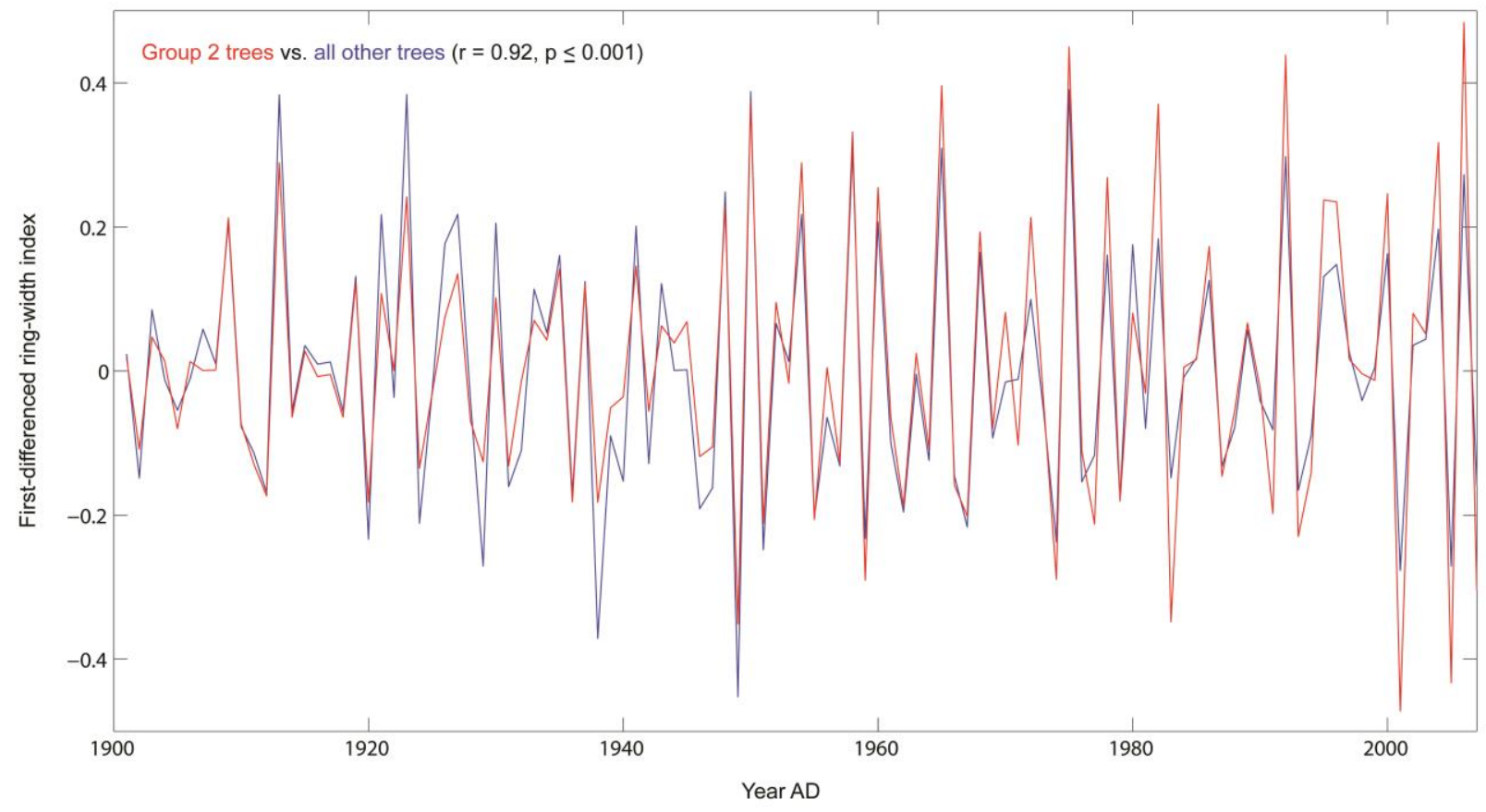

1

2 Supplementary Figure 9. A comparison of average first-differenced ring-width indices from

3 Group 2 trees and all other trees from the Mackenzie Delta regional site network.

4

5

6

7

8

9

10

11

12

13

14

15 
Briffa, K.R., 2000. Annual climate variability in the Holocene: Interpreting the message of ancient trees. Quaternary Science Reviews 19, 87-105.

4 Burn, C.R., Kokelj, S. V, 2009. The environment and permafrost of the Mackenzie Delta area.

5 Permafrost and Periglacial Processes 20, 83-105.

6 Cook, E.R., 1985. A Time Series Analysis Approach to Tree Ring Standardization. PhD

7 dissertation. University of Arizona, Tuscon, USA, $171 \mathrm{pp}$.

8 D’Arrigo, R., Jacoby, G., Buckley, B., Sakulich, J., Frank, D., Wilson, R., Curtis, A.,

9 Anchukaitis, K., 2009. Tree growth and inferred temperature variability at the North American arctic treeline. Global and Planetary Change 65, 71-82.

11 D'Arrigo, R., Wilson, R., Jacoby, G., 2006. On the long-term context for late twentieth century 12 warming. Journal of Geophysical Research 111, doi:10.1029/2005JD006352.

13 Esper, J., Cook, E.R., Schweingruber, F.H., 2002. Low-frequency signals in long tree-ring 14 chronologies for reconstructing past temperature variability. Science 295, 2250-2253.

15 Frank, D., Esper, J., Cook, E.R., 2007. Adjustment for proxy number and coherence in a largescale temperature reconstruction. Journal of Geophysical Research 34,

17 doi:10.1029/2007GL030571.

Holmes, R.L., 1983. Computer-assisted quality control in tree-ring dating and measurement. Tree-Ring Bulletin 43, 69-78.

20 Jones, P.D., Briffa, K.R., Barnett, T.P., Tett, S.F.B., 1998. High-resolution palaeoclimatic

21 records for the last millennium: interpretation, integration and comparison with General

22 Circulation Model control-run temperatures. The Holocene 8, 455-471.

23 Kaufman, D.S., Schneider, D.P., McKay, N.P., Ammann, C.M., Bradley, R.S., Briffa, K.R., 24 Miller, G.H., Otto-Bliesner, B.L., Overpeck, J.T., Vinther, B.M., and Arctic Lakes 2k Project

25 Members, 2009. Recent warming reverses long-term Arctic cooling. Science 325, 1236-1239.

26 Mekis, É., Vincent, L.A., 2011. An overview of the second generation adjusted daily 27 precipitation dataset for trend analysis in Canada. Atmosphere-Ocean 49, 163-177.

28 Pearce, C.M., McLennan, D., Cordes, L.D., 1988. The evolution and maintenance of white 29 spruce woodlands on the Mackenzie Delta, N.W.T., Canada. Holarctic Ecology 11, 248-258.

30 Porter, T.J., Pisaric, M.F.J., 2011. Temperature-growth divergence in white spruce forests of Old 31 Crow Flats, Yukon Territory, and adjacent regions of northwestern North America. Global 32 Change Biology 17, 3418-3430. 
1 Porter, T.J., Pisaric, M.F.J., Field, R.D., Kokelj, S. V, Edwards, T.W.D., deMontigny, P., Healy, 2 R., LeGrande, A.N., 2013. Spring-summer temperatures since AD 1780 reconstructed from

3 stable oxygen isotope ratios in white spruce tree-rings from the Mackenzie Delta, northwestern

4 Canada. Climate Dynamics, doi:10.1007/s00382-013-1674-3.

5 Porter, T.J., Pisaric, M.F.J., Kokelj, S. V, Edwards, T.W.D., 2009. Climatic signals in $\delta^{13} \mathrm{C}$ and

$6 \quad \delta^{18} \mathrm{O}$ of tree-rings from white spruce in the Mackenzie Delta region, northern Canada. Arctic,

7 Antarctic, and Alpine Research 41, 497-505.

8 Szeicz, J.M., MacDonald, G.M., 1995. Dendroclimatic reconstruction of summer temperatures in

9 northwestern Canada since A.D. 1638 based on age-dependent modelling. Quaternary Research

10 44, 257-266.

11 Szeicz, J.M., MacDonald, G.M., 1996. A 930-year ring-width chronology from moisture-

12 sensitive white spruce (Picea glauca Moench) in northwestern Canada. The Holocene 6, 345-

13351.

14 Wahl, E.R., Ammann, C.M., 2007. Robustness of the Mann, Bradley, Hughes reconstruction of 15 Northern Hemisphere surface temperatures: Examination of criticisms based on the nature and 16 processing of proxy climate evidence. Climatic Change 85, 33-69.

17 Wilson, R., D’Arrigo, R., Buckley, B., Büntgen, U., Esper, J., Frank, D., Luckman, B., Payette, 18 S., Vose, R., Youngblut, D., 2007. A matter of divergence: Tracking recent warming at

19 hemispheric scales using tree ring data. Journal of Geophysical Research 112,

20 doi:10.1029/2006JD008318. 